Walter De Biase da Silva Neto

\title{
AVALIAÇÃO INTRA-OPERATÓRIA DA PRESSÃO PORTAL E RESULTADOS DO TRATAMENTO CIRÚRGICO DA HIPERTENSÃO PORTAL EM PACIENTES ESQUISTOSSOMÓTICOS
}

Dissertação apresentada à Faculdade de Medicina da Universidade de São Paulo para obtenção de título de Mestre em Ciências.

Área de concentração: Cirurgia do Aparelho Digestivo

Orientador: Dr. Paulo Herman

SÃO PAULO

2003 
FICHA CATALOGRÁFICA

Preparada pela Biblioteca da

Faculdade de Medicina da Universidade de São Paulo

Creprodução autorizada pelo autor

Silva Neto, Walter De Biase da

Avaliação intra-operatória da pressão portal e resultados do tratamento cirúrgico da hipertensão portal em pacientes esquistossomóticos / Walter De Biase da Silva Neto. -- São Paulo, 2003.

Dissertação(mestrado)--Faculdade de Medicina da Universidade de São Paulo. Departamento de Gastroenterologia.

Área de concentração: Cirurgia do Aparelho Digestivo.

Orientador: Paulo Herman.

Descritores: 1.ESTUDOS DE AVALIAÇÃO 2.RESULTADO DE TRATAMENTO 3.PRESSÃO NA VEIA PORTA 4.HIPERTENSÃO PORTAL/cirurgia 5.VARIZES ESOFÁGICAS E GÁSTRICAS/cirurgia 6.MONITORIZAÇÃO INTRA-OPERATÓRIA/métodos 7.ESQUISTOSSOMOSE MANSONI/cirurgia 8.ESQUISTOSSOMOSE MANSONI/etiologia

9.ESPLENECTOMIA/métodos 10.SEGUIMENTOS 
Aos meus pais Walter (in memorian) e Anastasia

À minha esposa Flávia

Aos meus amados filhos

"que me ensinaram a compreender o mundo"

Vitor, Bruna e Lara 


\section{AGRADECIMENTOS}

Ao Dr. Paulo Herman, pela dedicação e disponibilidade. Apaziguador nos momentos de ansiedade e estimulador nos momentos de quietude, demonstrando conhecimento e capacidade na condução deste trabalho.

Ao Dr. Adalberto Cavarzan, pioneiro da cirurgia de hipertensão portal em nosso meio e realizador das primeiras operaçöes do nosso estudo, despertando o meu interesse pelo assunto.

Ao Prof. Dr. Bruno Zilberstein, pela coragem e confiança ao assumir a coordenação deste mestrado.

Ao Prof. Dr. Joaquim Gama-Rodrigues, que como Chefe do Serviço de Cirurgia do Aparelho Digestivo da Faculdade de Medicina da USP deu apoio integral a este mestrado.

Aos Chefes do Serviço de Cirurgia Geral da Faculdade de Medicina da Universidade Federal de Goiás, Dr. Manoel Maria Pereira dos Santos e Dr. Luiz Arantes, pela compreensão e disponibilidade do Serviço para realização do nosso estudo.

Ao Dr. Joffre Marcondes Rezende Filho, pelo excelente trabalho de acompanhamento endoscópico dos pacientes. 
Ao Dr. Leozarte Alves e Dr. Hélio Ponciano Trevenzol que se doaram ao suporte e organização de toda a infra-estrutura deste mestrado.

Ao Dr. Américo de Oliveira Silvério pelo inestimável auxílio na composição deste trabalho.

À Dra. Cláudia Naves Battlehner pela presteza, precisão e competência no processo de tradução do trabalho.

Aos médicos que participaram das operações feitas em nosso estudo: Dr. Arturo Bermudes (in memorian); Dr. Fernando Correia Amorim; Dr. Claudemiro Quirenze Jr.

Aos funcionários do SAME do Hospital das Clínicas da Faculdade de Medicina da UFG. Pela disponibilidade na busca dos prontuários dos pacientes, tarefa nem sempre fácil.

As secretárias da Pós-graduação da Faculdade de Medicina da UFG, Patrícia Menezes dos Santos e Andreia Pereira dos Santos.

A bibliotecária Maria Raquel Gomes da Silva, pela precisão na pesquisa de trabalhos científicos

À Sra. Andréa Borges Melo pelo talento na ilustração deste trabalho. 
SILVA NETO, W.D.B. Avaliação intra-operatória da pressão portal e resultados do tratamento cirúrgico da hipertensão portal em pacientes esquistossomóticos. São Paulo 2003. Dissertação (Mestrado). Faculdade de Medicina da Universidade de São Paulo.

\section{$\underline{\text { Resumo: }}$}

No Brasil a principal causa de hipertensão portal é a esquistossomose mansônica na sua forma hepato-esplênica, classificada como pré-sinusoidal. Esta doença adquire grande importância epidemiológica, por acometer indivíduos jovens, com função hepática preservada, e por atingir uma grande parcela da população (cerca de 1 milhão de indivíduos). Destes, cerca de 12 a 52\% irão apresentar hemorragia digestiva por ruptura de varizes de esôfago.

Não existe até o momento nenhum tratamento que se estabeleça como de consenso para esta enfermidade, porém há uma preferência dos autores para o tratamento cirúrgico e, no Brasil, esta recai sobre a desconexão ázigo-portal e esplenectomia geralmente associada a escleroterapia endoscópica das varizes no pós-operatório. Não estão bem estabelecidas as alterações hemodinâmicas portais decorrentes do tratamento cirúrgico da hipertensão portal e sua influência no resultado deste tratamento.

Com o objetivo de avaliar o impacto imediato da desconexão ázigo-portal e esplenectomia (DAPE) na pressão portal e os resultados do tratamento cirúrgico da hipertensão portal no que se refere à recidiva hemorrágica e ao calibre das varizes 
de esôfago, foram estudados 19 pacientes portadores de esquistossomose hepatoesplênica e hipertensão portal com história de hemorragia digestiva alta por ruptura de varizes esofágicas, com idade média de 37,9 anos. Durante a cirurgia foi avaliada a pressão portal, no início e no final do procedimento através da cateterização da veia porta por cateter de polietileno introduzido por veia jejunal. Todos os pacientes foram submetidos à endoscopia no pré e pós-operatório para avaliar a variação do calibre das varizes esofágicas. Os pacientes foram acompanhados ambulatorialmente e o tempo médio de seguimento foi de 26 meses.

Como resultado obteve-se uma queda na pressão portal média de $31,3 \%$ após a DAPE $(p=0,0001)$. No acompanhamento pós-operatório houve redução significativa do calibre das varizes esofágicas quando comparadas com a avaliação pré-operatória $(p<0,05)$. Apenas um paciente $(8,3 \%)$ apresentou, durante 0 acompanhamento, recidiva hemorrágica porém, esta foi decorrente de úlcera gástrica e não de varizes esofágicas.

Por fim chegou-se à conclusão de que a desconexão ázigo-portal e esplenectomia promoveu queda imediata na pressão portal, com conseqüente diminuição do calibre das varizes esofágicas, tendo sido eficaz no tratamento da hipertensão portal destes pacientes. 
SILVA NETO, W. D. B. Intraoperative evaluation of the portal pressure and the immediate results of the surgical treatment of the portal hypertension in patients with schistosomiasis. São Paulo 2003. Dissertação (Mestrado). Faculdade de Medicina Universidade de São Paulo.

\section{Abstract:}

The main cause of portal hypertension in Brazil is the hepato-splenic form of mansonic schistosomiasis, which is classified as pre-sinusoidal. It acquires major epidemiological importance because it occurs in young individuals and affects a huge parcel of the population (around 1 million people), 12 to $52 \%$ of whom will present digestive hemorrhage due to rupture of esophageal varices.

There is no consensus treatment for this disease up to the moment, but there is a predilection for the surgical approach. In Brazil, the most employed technique is the esophagogastric devascularization with splenectomy (EGDS), generally associated to late postoperative endoscopical sclerotherapy of the esophageal varices. The hemodynamic alterations in the portal flow resulting from the surgery and their possible influences on the outcome are not well established.

With the aim of evaluating the immediate impact of the EGDS upon the portal pressure as well as the results of the surgical treatment on the digestive hemorrhage recurrence and the caliber of the esophageal varices, 19 patients (11males, aged between 18 and 61 years) with hepato-splenic schistosomiasis, presenting portal hypertension and previous episodes of digestive hemorrhage were studied. None of the patients had received any treatment prior to the surgery. The portal pressure was assessed at the beginning and the end of the EGDS through catheterization of the 
portal vein with a polyethylene catheter introduced through a branch of a jejunal vein. All the patients were submitted to digestive endoscopy before and after the surgery (2 months), in order to classify the caliber of the esophageal varices according to Palmer's classification. They also entered the continuous program of endoscopical evaluation and sclerotherapy. The mean clinical follow up period was 26 months.

Our results showed that the portal pressure had diminished in all the patients, with a mean decrease of $31.3 \%$ after the EGDS. In the postoperative follow up (1 month), the esophageal varices showed a statistically significant reduction in their calibers, when compared to the pre-surgical measurements $(p=0.004)$. Only one patient presented digestive hemorrhage during the follow up period, but it was due to gastric ulcer and not to rupture of esophageal varices.

These results have demonstrated that the EGDS promotes an immediate decrease in the portal pressure and a reduction in the caliber of the esophageal varices, thus contributing to the good results of this technique. With the association of EGDS and sclerotherapy of the esophageal varices, no hemorrhagic episodes were observed in this series, during the study. 


\section{LISTA DE ABREVIATURAS}

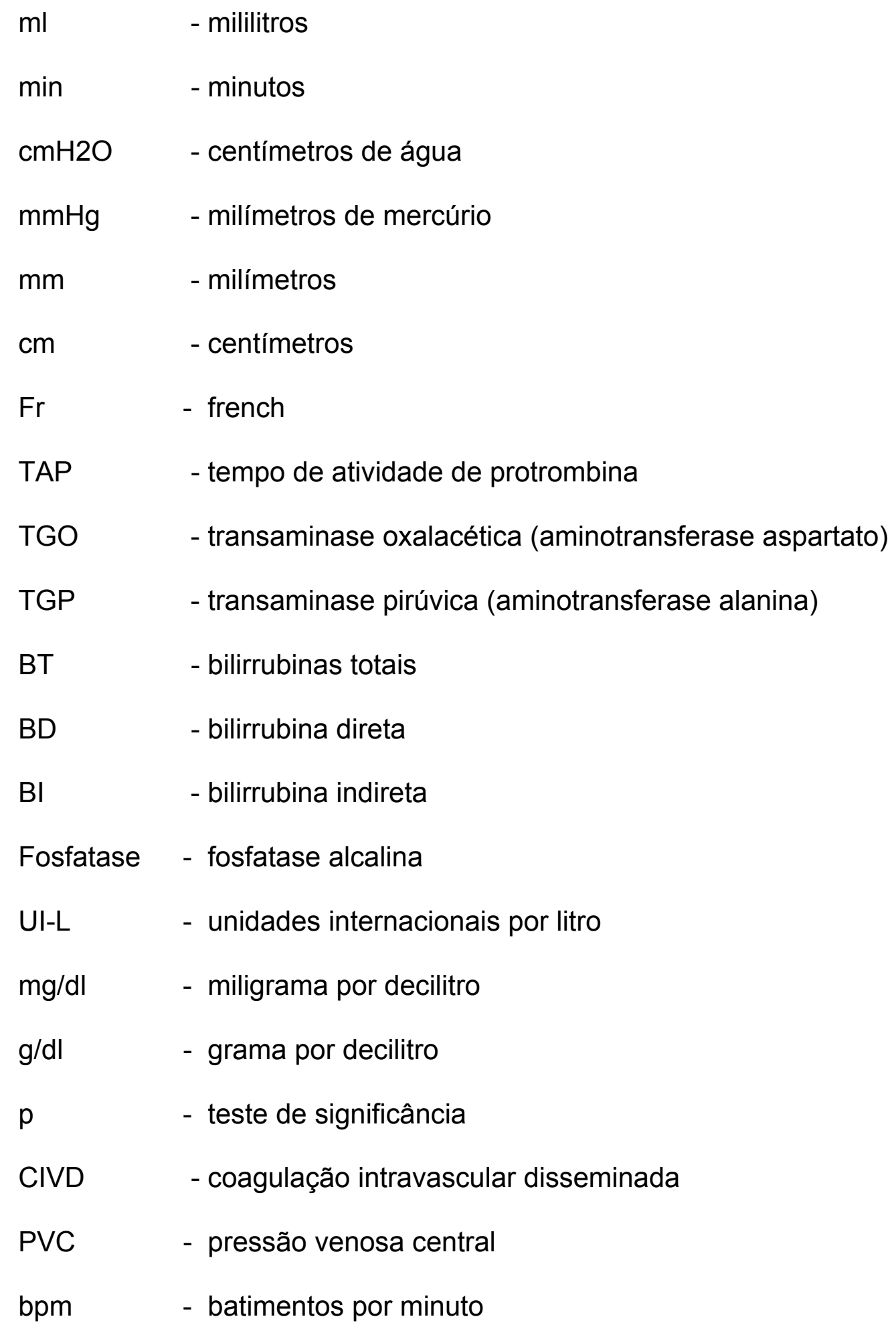




\section{SUMÁRIO}

1. INTRODUÇÂO

1.1 DEFINIÇÃO / CLASSIFICAÇÃO 1

1.2 ANATOMIA 2

1.3 FISIOPATOLOGIA 3

1.4 EPIDEMIOLOGIA

1.5 TRATAMENTO 6

1.6 AVALIAÇÃO HEMODINÂMICA PORTAL 9

2. OBJETIVOS 12

3. CASUISTICA E MÉTODOS 13

3.1 CASUÍSTICA 13

3.2 CRITÉRIOS DE INCLUSÃO 13

3.3 CRITÉRIOS DE EXCLUSÃO 14

3.4 MÉTODOS 14

3.4.1 AVALIAÇÃO LABORATORIAL PRÉ-OPERATÓRIA 14

3.4.2 AVALIAÇÃO ENDOSCÓPICA NO PRÉ-OPERATÓRIO

3.4.3 ESCLEROTERAPIA ENDOSCÓPICA PÓS-OPERATÓRIA 15

3.4.4 TRATAMENTO CIRÚRGICO / AVALIAÇÃO DA PRESSÃO
PORTAL INTRA-OPERATÕRIA

3.4.5 RESULTADOS IMEDIATOS DO TRATAMENTO CIRÚRGICO 18

3.5 ACOMPANHAMENTO AMBULATORIAL PÓS-OPERATÓRIO 18

3.6 AVALIAÇÃO ENDOSCÓPICA E ESCLEROTERAPIA
PÓS-OPERATÓRIA

$\begin{array}{ll}3.7 \text { ANÁLISE ESTATÍSTICA } & 18\end{array}$

4. RESULTADOS 20

4.1 AVALIAÇÃO LABORATORIAL 20

4.2 AVALIAÇÃO ENDOSCÓPICA PRÉ-OPERATÓRIA 21

4.3 AVALIAÇÃO HEMODINÂMICA SISTÊMICA NO INTRA-OPERATÓRIO 22

4.3.1 PRESSÃO ARTERIAL MÉDIA 22

4.3.2 FREQUÊNCIA CARDÍACA 22

4.4 AVALIAÇÃO DA PRESSÃO PORTAL INTRA-OPERATÓRIA 23

4.5 REPOSIÇÃO DE CONCENTRADO DE HEMÁCIAS 25

4.6 TEMPO OPERATÓRIO 26

4.7 COMPLICAÇÕES PÓS-OPERATÓRIAS 26 
4.8 MORTALIDADE OPERATÓRIA / PÓS-OPERATÓRIA

4.9 REOPERAÇÕES

4.10 TEMPO DE INTERNAÇÃO

4.11 ACOMPANHAMENTO AMBULATORIAL

31

4.12 AVALIAÇÃO ENDOSCÓPICA PÓS-OPERATÓRIA

5. DISCUSSÃO

6. CONCLUSÕES

7. ANEXOS

8. REFERÊNCIAS BIBLIOGRÁFICAS 
1 Introdução:

\subsection{Definição / Classificação}

A hipertensão portal pode ser definida como uma síndrome caracterizada por obstrução ao fluxo sanguíneo no território portal (PUGLIESI et al., 1994).

Esta síndrome pode ser classificada de acordo com o nível de obstrução ao fluxo portal em relação aos sinusóides hepáticos e subdividida em (SUMMERFIELD, 1994):

- Pré-sinusoidal extra-hepática (pré-hepática);

- Pré-sinusoidal intra-hepática;

- Sinusoidal;

- Pós-sinusoidal

Neste estudo abordaremos apenas a hipertensão portal pré-sinusoidal intrahepática, que caracteriza a esquistossomose mansônica, maior causa de hipertensão portal em nosso meio (CLEVA et al., 1998). 


\subsection{Anatomia}

A veia porta é formada pela junção de quatro veias, duas principais e duas secundárias. As duas principais, veia mesentérica superior e veia esplênica se encontram em ângulo agudo para formar o tronco da veia porta. A veia mesentérica superior carrea os nutrientes provenientes do intestino delgado e cólon direito que serão metabolizados no fígado, já a veia esplênica nutre os hepatócitos com insulina e glucagon provenientes do pâncreas. As veias secundárias são a mesentérica inferior que drena parte do cólon transverso e cólon esquerdo e a veia gástrica esquerda que drena a junção esôfago-gástrica, polo superior do estômago e área peri-cárdia, estando em conexão com as veias gástricas curtas, tuberositárias e veias peri-esofágicas além das para-esofágicas; todas elas estabelecem a conexão do sistema portal com a veia ázigos que, por sua vez, drenará para a veia cava superior (KELNER, 1992).

O sistema porta apresenta um fluxo sanguíneo que varia entre 1000 e 1200 $\mathrm{ml} / \mathrm{min}$ (PUGLIESI et al., 1994) e apresenta uma grande importância, já que constitui o único sistema, no homem, interposto a duas redes capilares, esplâncnica e hepática, atuando como verdadeiro mecanismo de comporta, regulando tanto a volemia como a pressão portal (KELNER, 1992). A pressão portal no homem sadio tem como limite inferior $6 \mathrm{cmH} 2 \mathrm{O}$ e superior $20 \mathrm{cmH} 2 \mathrm{O}$, situando-se o valor médio em 12,8 cmH2O (STELMACH et al., 1996). 


\subsection{Fisiopatologia}

Das espécies de Shistossoma existentes apenas o Shistossoma mansoni é encontrado nas Américas. Acredita-se que tenha chegado ao Brasil pelo tráfico de escravos vindos da África. Este verme trematodeo que apresenta cerca de $1 \mathrm{~cm}$ de comprimento quando adulto (AMATO NETO et al., 1991) habita, acasalado, a submucosa do cólon esquerdo do homem, seu hospedeiro definitivo, podendo viver aí por 30 anos ou mais.

Cada fêmea elimina cerca de 300 ovos por dia dos quais $25 \%$ são carreados através da veia mesentérica inferior em direção ao fígado. Os ovos ficam retidos nas finas ramificações terminais da veia porta nos espaços porta intra-hepáticos sem atingir os sinusóides. Da mesma maneira, parasitas adultos se desprendem da veia mesentérica inferior e vão obstruir as finas ramificações intrahepáticas da veia porta. Ao nível de tais obstruções por ovos e/ou parasitas mortos, desencadeia-se um processo inflamatório sequencial constituindo a fibrose de Symmers (SYMMERS, 1903), além da formação de granuloma no espaço porta (KELNER, 1992). Esta fibrose determina bloqueio hepático présinusoidal sendo responsável pela obstrução ao fluxo venoso portal e, consequentemente, um dos fatores de aumento da pressão no sistema porta.

O obstáculo ao fluxo portal leva a uma estase venosa no baço. Este componente, associado a uma intensa hiperplasia do sistema retículo endotelial esplênico, desencadeada pela infecção pelo Shisossoma mansoni, faz com que o órgão aumente o seu volume em até dez vezes. 
Outra consequência do represamento do sangue portal decorrente da hipertensão venosa é o desenvolvimento da circulação colateral do sistema porta que se encontra hipertenso em direção ao sistema cava de baixa pressão, que se estabelece em cinco sítios: quatro com o sistema cava inferior e um com o sistema cava superior. A conexão com a veia cava inferior se estabelece ao nível do retroperitôneo, reto, canal de Arantius e veias umbilicais. Já o sítio da veia cava superior é estabelecido ao nível da junção esôfago-gástrica e veia ázigos (KELNER, 1992).

Além do óbvio aumento na pressão portal causado pelo componente obstrutivo da fibrose hepática, o aumento no fluxo portal secundário a drenagem venosa de uma grande esplenomegalia também contribui como causa da hipertensão portal. Este aumento de fluxo portal deve-se também ao estado hiperdinâmico sistêmico desencadeado por um incremento no débito cardíaco e diminuição na resistência vascular periférica, pois nestes pacientes o baço atua como uma grande fístula arterio-venosa, com desvio do fluxo sanguíneo da circulação sistêmica em direção à circulação porta (RAIA, et al., 1991; CLEVA, 1996).

Como resultado deste aumento de pressão pela obstrução ao fluxo venoso portal o sangue é desviado para um território de menor pressão como o sistema cava e, sendo as veias do sistema portal desprovidas de válvulas, haverá uma inversão do fluxo, o chamado fluxo hepato-fugal (KELNER, 1992).Com o aumento da pressão portal para valores acima de 20 chegando a $30 \mathrm{mmHg}$ no advento da obstrução ao fluxo portal (PUGLIESI et al., 1994), ocorre uma dilatação das veias 
que drenam o sistema porta. Esta alteração ao nível da junção gastro-esofágica, produz varizes nesta região, cuja importância decorre do fato de serem susceptíveis a ruptura e consequente sangramento muitas vezes de grande volume, podendo levar ao óbito. A esquistossomose na sua forma hepatoesplênica, por habitualmente acometer adolescentes e indivíduos jovens com função hepática preservada, tem como a principal complicação e especialmente mortalidade, a hemorragia digestiva alta por rotura de varizes esofagianas que pode ocorrer em $11,7 \%$ dos pacientes (FERRAZ et al., 2001).

\subsection{Epidemiologia}

A esquistossomose assume grande importância na saúde pública quando as estimativas apontam que cerca de 200 milhões de pessoas são acometidas pelas suas variadas formas em países da Ásia, África, América do Sul e Caribe.

No Brasil a esquistossomose é doença endêmica com alta prevalência, atingindo de dez a doze milhões de pessoas (MACHADO, 1977; PRATA, 1982; COUTINHO e DOMINGUES, 1988), tornando-se a principal causa de hipertensão portal em nosso meio (CLEVA et al., 1998).

Cerca de 10\% dos indivíduos infectados pela esquistossomose mansônica apresentam a manifestação mais grave da doença, a forma hepato-esplênica segundo a classificação da Sociedade Brasileira de Hepatologia (COUTINHO e DOMINGUES, 1988). Assim, pelo menos um milhão de indivíduos em nosso meio apresentam hipertensão portal com varizes de esôfago, com um potencial de rotura e hemorragia entre $12 \%$ e $52 \%$ (MAHDY, 1978; CORNET et al., 1980; 
COURA et al., 1982; ABRANTES et al., 1983, CHAIB et al.,1983; de COCK, 1983; OBEID et al., 1983; EZZAT et al.,1986; BESSA et al.,1987; CURY, 1989), sendo esta a principal causa de mortalidade nestes pacientes (SILVA, 1991). Os índices de mortalidade não são desprezíveis, estimando-se que sua prevalência seja de 200 mil pessoas em todo o mundo, segundo relatório da Organização Mundial de Saúde de 1990, sendo a maioria destes, brasileiros.

\subsection{Tratamento}

Inúmeros métodos de tratamento foram idealizados e utilizados no sentido de controlar a hemorragia por varizes esôfago-gásticas em pacientes com esquistossomose na sua forma hepato-esplênica.

O tratamento clínico têm eficácia duvidosa, uma vez que não alcança o objetivo principal: eliminação ou pelo menos redução do calibre das varizes esofagianas, impedindo assim o ressangramento (STRAUSS,1983).

A escleroterapia endoscópica dos cordões varicosos nestes pacientes é acompanhada de índices elevados de ressangramento, variando entre 11 e 33,3\% (BESSA \& HELMY, 1984; SAKAI, 1985; AL-KARAWI et al., 1986; SAKAl et al., 1990; CORDEIRO, 1990; AL-KARAWI et al., 1996)

Por estes motivos, em nosso meio dá-se preferência ao tratamento cirúrgico. No passado as anastomoses porto-sistêmicas como: a anastomose porto-cava, meso-cava e espleno-renal clássica, foram empregadas e eram eficazes no controle do sangramento, no entanto, apresentaram complicações pós-operatórias severas, destacando-se altos índices de encefalopatia porto- 
sistêmica que variavam entre 26 e 69\% (ROCHA, 1957; SILVA, 1961; OKUMURA, 1967; SPERANZINI, 1971; GUIMARÃES, 1973; RANGEL, 1990; RAIA, 1994). Na tentativa de minimizar as conseqüências fisiopatológicas do desvio total de sangue portal, surgiram as derivações venosas seletivas, como a derivação espleno-renal seletiva (WARREN et al., 1967), técnica que até certo ponto atingiu seu objetivo, porém ainda sendo acompanhada de índices consideráveis de encefalopatia porto-sistêmica pós-operatória, entre 3,3 e 14,8\% como mostram estudos feitos nos centros que empregavam a derivação esplenorenal distal no controle da hemorragia digestiva na esquistossomose forma hepato-esplênica (SAAD et al., 1977; PITANGA, 1986; EZZAT et al., 1986; EZZAT et al., 1990; STRAUSS et al., 1989; CURRY, 1990; ABRANTES, 1988; ABRANTES, 1991; RAIA et al., 1994). No contexto da hipertensão portal, na qual não há comprometimento da função hepática, como no caso específico da esquistossomose em que a encefalopatia não faz parte do quadro clínico, o emprego destes procedimentos como tratamento se torna pouco aconselhável. Atualmente as cirurgias mais empregadas podem ser divididas em duas modalidades: derivações venosas seletivas que objetivam a descompressão seletiva do território portal esquerdo, sítio das varizes esofagianas e as desconexões ázigo-portais, que visam interromper a circulação colateral do sistema portal em direção ao esôfago, onde há varizes (CAPUA Jr et al., 1992).

A opção para tratamento cirúrgico que visa desconectar a veia porta do território das varizes esofágicas que drenam para o sistema ázigos, foi descrita em 1967, por HASSAB, como a técnica de desvascularização esôfago-gástrica por via 
abdominal associada a esplenectomia, com baixas taxas de mortalidade e recidiva hemorrágica. Em 1973, SUGIURA \& FUTUGAWA, descreveram um outro procedimento semelhante utilizando agora a via tóraco-abdominal para devascularização esôfago-gástrica com esplenectomia e acrescentando a transecção esofágica também com resultados satisfatórios. No entanto, em nosso meio, dá-se preferência a desvascularização por via abdominal.

A desconexão ázigo-portal e esplenectomia é acompanhada de índices de ressangramento que variam entre 6 e 29\%, porém sem o inconveniente da encefalopatia porto-sistêmica (HASSAB, 1967; EL MASRI et al., 1982; KELNER et al., 1982; CHAIB et al., 1983; EZZAT et al., 1990; RAIA et al., 1994; FERRAZ, 2000). Com o intuito de diminuir a recidiva hemorrágica após estes procedimentos alguns autores associam durante a desvascularização, a abertura do esôfago e a sutura direta das varizes (LEMOS-TORRES \& DEGNI, 1966; HADDAD et al., 1982; KELNER et al., 1982; CHAIB et al., 1983; RAIA et al., 1994), procedimento que é acompanhado de aumento no número de complicações e de óbitos por fístulas digestivas (HADDAD et al., 1982), estando hoje esta técnica em desuso. $\mathrm{Na}$ tentativa de substituir estas técnicas de abordagem direta das varizes esofagianas durante o ato operatório, com maior potencial de complicação, surgiu a opção da abordagem endoscópica pós-operatória através de escleroterapia ou ligadura elástica.

Em estudo realizado em 1990, SAKAl et al. mostraram que quando associada à esplenectomia prévia, a escleroterapia endoscópica era mais eficaz que a escleroterapia isolada no tratamento da hemorragia digestiva por varizes 
esofagianas apresentando uma queda nas taxas de ressangramento para valores abaixo de $7 \%$, dado corroborado por estudo feito por PUGLIESE, em sua Tese de

Doutorado em 1996, que mostrou taxa de ressangramento de $5,1 \%$ em pacientes submetidos a desconexão ázigo-portal seguida de escleroterapia endoscópica pós-operatória.

Não existe um consenso sobre qual a melhor técnica para o tratamento da hipertensão portal na esquistossomose forma hepato-esplênica, a desconexão ázigo-portal ou a derivação porto sistêmica seletiva, pois faltam estudos controlados a este respeito.

\subsection{Avaliação hemodinâmica portal}

Com o intuito de melhor avaliar a fisiopatologia da hipertensão portal, bem como o impacto do tratamento cirúrgico no sistema portal propriamente dito, e com isso obter dados para avaliar qual a melhor cirurgia, alguns autores têm estudado a hemodinâmica portal ao longo dos anos, quer seja através de punção transparietal do sistema porta: trans-hepática (BRUNO, et al., 1983;), intraesplênica (DANTAS, 1954), por cateterização de veias hepáticas (PATON, et al., 1953), ou por punção das veias retais (SAAD Jr., 1981), quer seja através de medidas pressóricas diretas durante o ato cirúrgico (SAAD Jr., 1981; SAAD Jr. et al., 1987), ou ainda diretamente nas varizes esofagianas por punção ou por manometria acoplada a um endoscópio (MOSIMANN, 1982; MOSIMANN et al., 1983; LACERDA et al., 1998). 
Embora trabalhos como o de LAUDANNA (1972); STRAUSS (1973) e PUGLIESI et al. (1995) que utilizando radioisótopos sugeriram que o fluxo hepático total encontra-se preservado em pacientes com a forma hepatoesplênica da esquistossomose, outros autores mostraram aumento no fluxo portal e consequente diminuição no fluxo arterial hepático (MIES et al., 1980; MORALI et al., 1991; RAIA, 1980). Corroboram para a teoria do aumento de fluxo portal trabalhos utilizando radioisótopos, ultra-som doppler e termodiluição de MORIYASU et al., 1991, AZEVEDO et al., 1988 e MIES, 1992, respectivamente.

CLEVA em sua tese de doutorado (1996) estudou o fluxo portal após a desconexão ázigo-portal e esplenectomia em pacientes esquistossomóticos e demonstrou uma queda real de $28 \%$ no fluxo portal após a cirurgia implicando como fatores responsáveis por esta queda a retirada do fluxo esplênico e a normalização do estado hiperdinâmico sistêmico após a esplenectomia. O mesmo autor constatou neste estudo um fluxo sistêmico hiperdinâmico com aumento do débito cardíaco e queda na resistência vascular sistêmica que no paciente esquistossomótico poderia ser atribuído ao hiperfluxo esplênico e à esplenomegalia. Neste caso, o baço funcionaria como uma grande fístula artériovenosa entre a circulação sistêmica (conduzida pela artéria esplênica) e o sistema porta (escoado pela veia esplênica). Um forte indício da validade desta teoria é a normalização dos parâmetros hemodinâmicos logo após a ligadura da artéria esplênica durante a desconexão ázigo-portal e esplenectomia. Além disto, utilizando cateter de termodiluição Edwards Swan-Ganz, introduzido na veia porta através de cateterização de ramo venoso do meso jejunal verificou queda 
acentuada da pressão portal (30\%) logo após a ligadura da artéria esplênica, que se manteve estável até o final do procedimento. No entanto, os resultados dos procedimentos cirúrgicos sobre a pressão portal em pacientes esquistossomóticos, são pouco conhecidos. Alguns estudos concluem que não há diferença significativa entre a pressão na veia porta no início da cirurgia e após a desconexão ázigo-portal (CAPUA Jr. et al.,1992;). STELMACH et al. em 1996 através de cateterização da veia gastro-epiplóica direita concluíram que a pressão portal não sofre alteração no período pós-operatório imediato.

Desta forma, pode-se perceber que ainda existem muitas controvérsias e indagações no que tange as alterações hemodinâmicas portais em portadores de esquistossomose na sua forma hepato-esplênica.

Neste estudo, onde descrevemos nossa experiência no tratamento eletivo de pacientes portadores de esquistossomose forma hepato-esplênica com hemorragia digestiva alta prévia, através da desconexão ázigo-portal mais esplenectomia, procuramos avaliar o impacto deste procedimento cirúrgico na pressão portal intra-operatória, na evolução das varizes esofagianas e recidiva hemorrágica no período pós-operatório. 


\section{$\underline{2 \text { - Objetivos }}$}

2.1 - Avaliar o impacto imediato da desconexão ázigo-portal associada à esplenectomia na pressão portal.

2.2 - Avaliar os resultados do tratamento cirúrgico da hipertensão portal por esquistossomose forma hepato-esplênica tratados por desconexão ázigoportal mais esplenectomia. 


\section{3 - Casuística e métodos:}

\section{1 - Casuística}

Foram estudados retrospectivamente 19 pacientes portadores de hipertensão portal decorrente de esquistossomose hepato-esplênica, sendo 11 do sexo masculino e 8 do feminino, com idade média de 37,9 anos (variando entre 18 e 61 anos), com história de hemorragia digestiva alta por ruptura de varizes de esôfago. Todos foram submetidos a tratamento cirúrgico de forma eletiva (desconexão ázigo-portal e esplenectomia), e não haviam sido submetidos a nenhum tipo de tratamento clínico ou endoscópico prévio. Dezessete operados no Departamento de Clínica Cirúrgica da Faculdade de Medicina da Universidade Federal de Goiás e dois no Serviço de Cirurgia Geral do Hospital Geral de Goiânia no período entre janeiro de 1992 e março de 2001, pela mesma equipe.

\section{2 - Critérios de inclusão}

Os critérios de inclusão no estudo foram:

- Diagnóstico de esquistossomose mansônica baseado em evidências epidemiológicas, clínicas e confirmados por exame histopatológico;

- Presença de antecedente de hemorragia digestiva alta por rotura de varizes de esôfago. 


\section{3 - Critérios de exclusão}

Foram excluídos do estudo pacientes com:

- História de etilismo crônico;

- Evidência clínica ou laboratorial de insuficiência hepato-celular;

- Sorologia positiva para hepatite B e/ou C;

- Evidência de outras hepatopatias ao exame histopatológico.

\section{4 - Métodos}

\subsection{1 - Avaliação laboratorial pré-operatória}

Todos os pacientes foram submetidos a avaliação laboratorial préoperatória de rotina (hemograma, uréia, creatinina, glicemia, radiografia de tórax e eletrocardiograma) e da função hepática, tendo como base os seguintes exames: albumina, TAP, TGP, TGO, bilirrubinas totais, diretas, indiretas e fosfatase alcalina.

\subsection{2 - Avaliação endoscópica no pré-operatório}

Todos os pacientes foram submetidos a exame endoscópico no período pré-operatório.

As varizes esofagianas foram avaliadas por endoscopia e classificadas de acordo com o seu diâmetro (segundo classificação de PALMER e BRICK, 1956)

Grau I = varizes com diâmetro inferior a $3 \mathrm{~mm}$

Grau II = varizes com diâmetro entre 3 e 6 mm 
Grau III = varizes com diâmetro superior a 6 mm

\subsection{3 - Escleroterapia endoscópica pós-operatória}

A avaliação endoscópica era feita a partir do $60^{\circ}$ pós-operatório e a necessidade de escleroterapia era determinada pelo endoscopista. A escleroterapia endoscópica pós-operatória utilizou o oleato de monoetanolamina associada a glicose $50 \%$, concentrado a $2,5 \%$ com volume de cerca de $20 \mathrm{ml}$, sendo realizada inicialmente com intervalo de 7 a 21 dias, a seguir a cada 30 dias, 6 meses, e finalmente a cada ano de acordo com a necessidade estabelecida pelo endoscopista para controle e/ou erradicação das varizes esofágicas. A injeção do agente esclerosante foi realizada por via intravasal e ao longo do mesmo cordão varicoso.

\subsection{4 - Tratamento cirúrgico / Avaliação da pressão portal intra-operatória}

A cirurgia era realizada eletivamente com o paciente sob anestesia geral em decúbito dorsal horizontal, com monitorização intra-operatória da frequência cardíaca, pressão venosa central (nos últimos dois casos) e pressão arterial média invasiva. A técnica operatória consistiu de laparotomia mediana desde o apêndice xifóide até a cicatriz umbilical; biópsia hepática em cunha do lobo direito para estudo histopatológico; cateterização de ramo venoso mesentérico (do meso jejunal) com cateter de polietileno com calibre de $6 \mathrm{Fr}$ e progressão deste no sentido da veia porta por uma extensão de cerca de $15 \mathrm{~cm}$, sendo sua localização confirmada pela palpação do cateter no interior da veia porta. O cateter era 
conectado a um sistema de coluna de água graduado em centímetros, estando a marca inicial ao nível da linha axilar média; aferição da pressão portal inicial concomitante a da pressão arterial, frequência cardíaca e nos últimos dois casos da pressão venosa central. Ligadura prévia da artéria esplênica ao nível da transição corpo-caudal do pâncreas com posterior esplenectomia. Procedia-se então a desvascularização do terço inferior do esôfago, fundo e corpo gástrico, vasos breves, preservando os nervos vagos, seguida de ligadura dos vasos da pequena curvatura desde a incisura angularis até uma extensão de 5 a $7 \mathrm{~cm}$ no sentido proximal no esôfago. Realizava-se então uma gastro-fundoplicatura póstero-lateral (2/3 por uma extensão longitudinal de $5 \mathrm{~cm}$ ) (Figura 1). Ao final do procedimento, aferição da pressão portal concomitante a da pressão arterial e frequência cardíaca com posterior retirada do cateter mesentérico-portal. Fechamento da cavidade por planos.

\subsection{5 - Resultados imediatos do tratamento cirúrgico}

Foram avaliadas as complicações pós-operatórias; mortalidade; reoperações; e período de internação.

\section{5 - Acompanhamento ambulatorial pós-operatório}

Após a alta hospitalar os pacientes eram acompanhados ambulatorialmente, inicialmente a cada trinta dias e após o sexto mês a cada seis meses, sendo avaliados clínica e endoscopicamente. 
Figura 1 - Esquema da desconexão ázigo-portal e esplenectomia

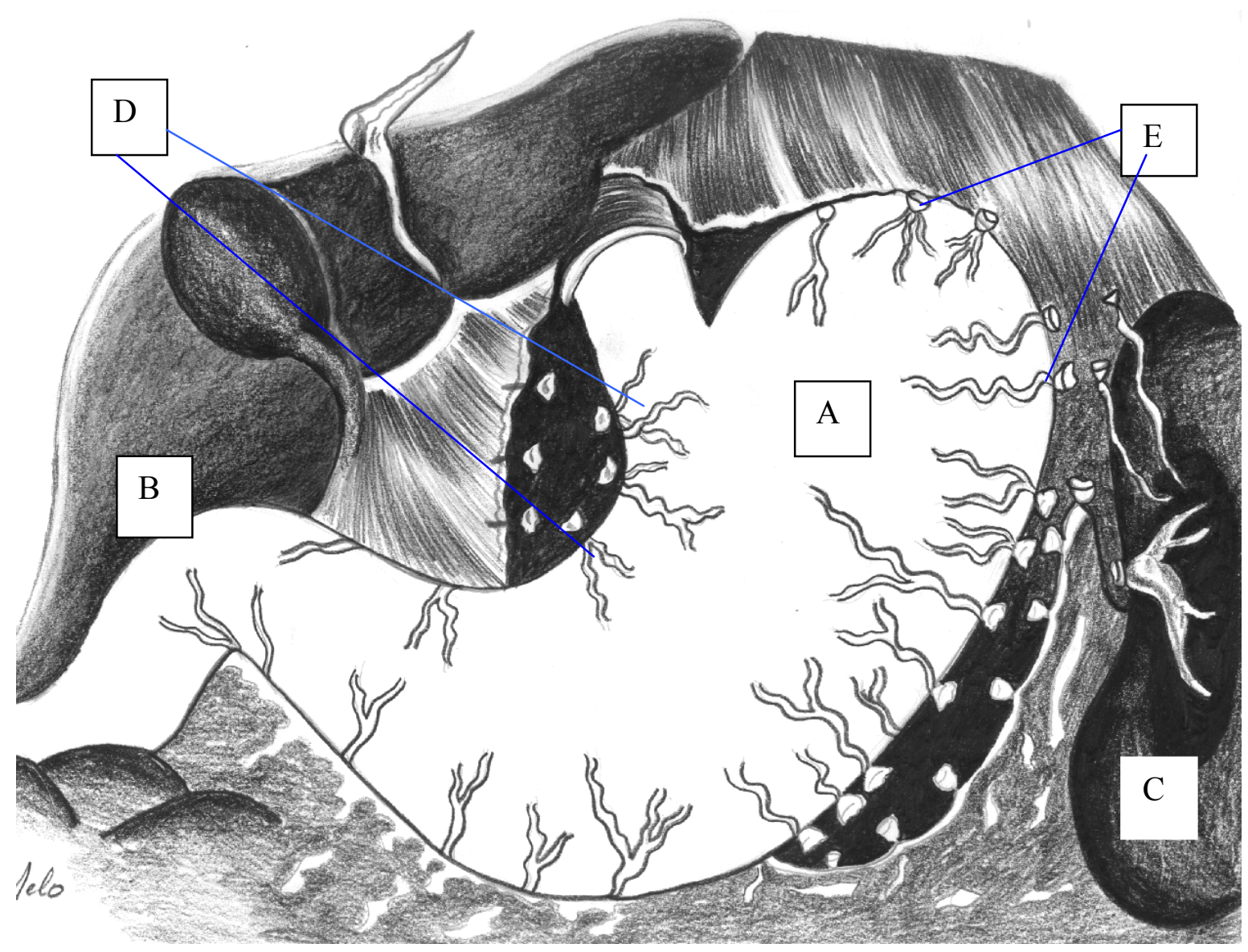

A: estômago; B: fígado; C: baço; D: ligadura dos vasos da pequena curvatura gástrica, desde a incisura angularis até o esôfago distal; E: ligadura dos vasos da grande curvatura gástrica. 


\section{6 - Avaliação endoscópica e escleroterapia pós-operatória}

A avaliação endoscópica pós-operatória era realizada a partir do segundo mês de pós-operatório. A análise das varizes consistiu na avaliação se: desapareciam, diminuíam, aumentavam ou permaneciam inalteradas, sendo considerados os exames realizados no pós-operatório precoce aqueles entre dois e seis meses e no pós-operatório tardio aqueles realizados a partir de seis meses.

\section{7 - Análise Estatística}

Foram analisados:

A - Os parâmetros hemodinâmicos (sistêmicos e portais) intra-operatórios, pré e pós desconexão ázigo-portal e esplenectomia

1- pressão arterial média

2- frequência cardíaca

3- pressão portal

B - O Calibre das varizes esofágicas nos períodos

1- pré-operatório

2- pós-operatório precoce

3- pós-operatório tardio

A análise dos resultados obtidos foi realizada através de testes estatísticos em que para variáveis quantitativas foi usado o teste paramétrico $t$ de student para dados pareados que se referem ao mesmo grupo de pacientes, com 
informações em períodos distintos; e o não-paramétrico de Wilcoxon para dados qualitativos no decorrer do tempo. 


\section{4 - Resultados}

\section{1 - Avaliação laboratorial pré-operatória}

No período pré-operatório, do total de pacientes operados, quatorze apresentavam anemia (73,6\%) quinze leucopenia (79\%) e dezessete plaquetopenia $(89,4 \%)$; três pacientes apresentavam aumento da fosfatase alcalina e dois da bilirrubina total (10,5\%). Nenhum paciente apresentava alterações nas dosagens de albumina, provas de coagulação (tempo de atividade de protrombina) ou transaminases. O resultado das provas bioquímicas de função hepática são mostrados na Tabela 1.

Tabela 1. Média dos valores da avaliação laboratorial pré-operatória da função hepática

\begin{tabular}{lc}
\hline Exame laboratorial & $\begin{array}{c}\text { Média } \\
\text { dos resultados }\end{array}$ \\
\hline Albumina $(\mathrm{g} / \mathrm{dl})$ & $4,06 \pm 0,46$ \\
TAP $(\%)$ & $86,45 \pm 8,03$ \\
TGP $(\mathrm{Ul} / \mathrm{L})$ & $24,27 \pm 11,21$ \\
TGO (Ul/L) & $27,73 \pm 10,70$ \\
BT (mg/dl) & $0,80 \pm 0,26$ \\
BD (mg/dl) & $0,45 \pm 0,23$ \\
BI (mg/dl) & $0,35 \pm 0,14$ \\
Fosfatase $(\mathrm{Ul} / \mathrm{L})$ & $238,00 \pm 104,73$ \\
\hline
\end{tabular}




\section{2 - Avaliação endoscópica pré-operatória}

Dos dezenove pacientes avaliados endoscopicamente no período préoperatório, dezesseis apresentavam varizes esofágicas Grau III (84,2\%); um varizes esofágicas Grau II (5,3\%) e dois apresentavam varizes esofágicas Grau I $(10,5 \%)$ (Tabela 2). Em nenhum paciente foram encontradas varizes de fundo gástrico.

Tabela 2. Avaliação endoscópica das varizes esofágicas no pré-operatório

\begin{tabular}{lcr}
\hline Classificação & \multicolumn{2}{c}{ Pré-operatório } \\
\cline { 2 - 3 } Segundo Palmer & Número & $\%$ \\
\hline 0 & - & 0,0 \\
I & 2 & 10,5 \\
II & 1 & 5,3 \\
III & 16 & 84,2 \\
Total & 19 & 100,0 \\
\hline
\end{tabular}




\section{3 - Avaliação hemodinâmica sistêmica no intra-operatório}

\subsection{1 - Pressão arterial média}

A pressão arterial média não apresentou variação estatisticamente significativa quando comparados o início e o final da cirurgia. O que pode ser verificado na Tabela 3.

Tabela 3. Pressão arterial média no início e ao final da operação

\begin{tabular}{lcc}
\hline Período & $\begin{array}{c}\text { Pressão arterial média } \\
(\mathrm{mmHg})\end{array}$ & Desvio Padrão \\
\hline Inicio & 93,7 & 15,7 \\
Fim & 92,6 & 13,0
\end{tabular}

$\mathrm{P}=0,059$

\subsection{2 - Frequência cardíaca}

A frequência cardíaca no início e no final da cirurgia não apresentou diferença estatisticamente significativa, conforme é demonstrado na Tabela 4. 
Tabela 4. Freqüência cardíaca média no início e ao final da desconexão ázigoportal mais esplenectomia

\begin{tabular}{lcc}
\hline Período & $\begin{array}{c}\text { Frequência cardíaca média } \\
(\mathrm{bpm})\end{array}$ & Desvio Padrão \\
\hline Inicio & 83,6 & 11,1 \\
Fim & 84,4 & 11,7 \\
\hline
\end{tabular}

$\mathrm{P}=0,219$

\section{4 - Avaliação da pressão portal intra-operatória}

Todos os pacientes apresentaram queda da pressão portal quando se comparou o início da cirurgia e o final do procedimento. Dezessete pacientes (85\%) apresentaram queda da pressão portal acima de $20 \%$ e cinco $(26,3 \%)$ apresentaram queda da pressão portal acima de 40\%. Apenas dois pacientes $(10,5 \%)$ apresentaram queda inferior a $10 \%$ (Tabela 5). Este percentual de redução da pressão portal se mostrou estatisticamente significativo quando se comparou o início e final da desconexão ázigo-portal e esplenectomia. Em termos percentuais a queda média da pressão portal foi de $31,3 \%$ com desvio padrão de 12,47 como se pode observar na Tabela 6 e Figura 2. 
Tabela 5. Variação da pressão portal (Pp) no início e no final da desconexão ázigo-portal mais esplenectomia.

\begin{tabular}{cccc}
\hline Caso & Pp inicial $(\mathrm{cmH} 2 \mathrm{O})$ & Pp final $(\mathrm{cmH} 2 \mathrm{O})$ & $\begin{array}{c}\% \text { de } \\
\text { queda }\end{array}$ \\
\hline 1 & & 15 & 42,3 \\
2 & 26 & 27 & 27,1 \\
3 & 37 & 29 & 6,5 \\
4 & 31 & 22 & 40,6 \\
5 & 37 & 19 & 20,9 \\
6 & 24 & 19 & 34,5 \\
7 & 29 & 23 & 36,1 \\
8 & 36 & 21 & 8,7 \\
9 & 23 & 24 & 33,4 \\
10 & 36 & 24 & 36,9 \\
11 & 38 & 19 & 51,3 \\
12 & 39 & 20 & 31,1 \\
13 & 29 & 20 & 33,4 \\
14 & 30 & 24 & 20,0 \\
15 & 30 & 27 & 29,0 \\
16 & 38 & 26 & 23,6 \\
17 & 34 & 22 & 24,2 \\
18 & 29 & 22 & 42,1 \\
19 & 38 & 21 & 48,8 \\
\hline
\end{tabular}

Tabela 6. Pressão portal média no início e no final da desconexão ázigo-portal e esplenectomia

\begin{tabular}{lcc}
\hline & \multicolumn{2}{c}{ Média } \\
\cline { 2 - 3 } Pressão portal & Inicial & Final \\
$(\mathrm{cmH} 2 \mathrm{O})$ & $33,00 \pm 5,28$ & $22,32 \pm 3,43$ \\
\hline
\end{tabular}

$\mathrm{P}=0,0001$ 
Figura 2. Pressão portal média no início e no final da desconexão ázigo-portal e esplenecotmia

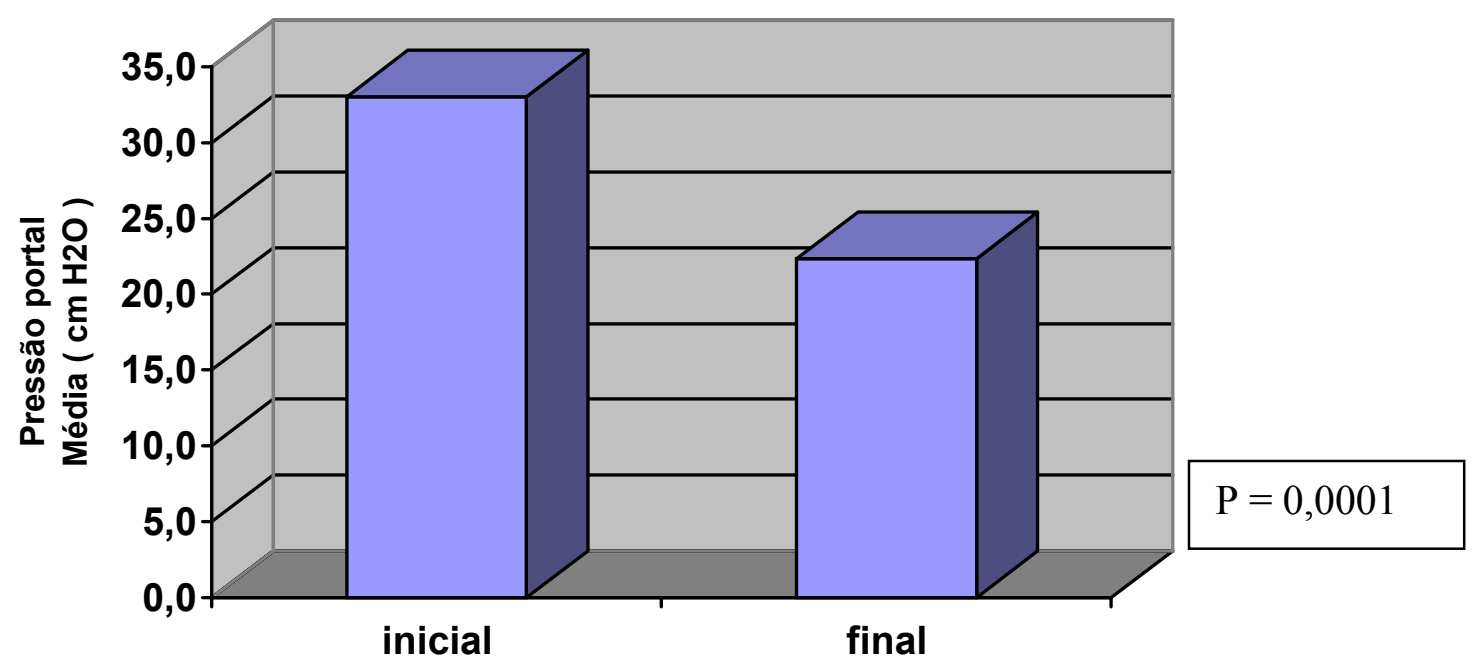

\section{5 - Reposição de cooncentrado de hemácias}

Foi necessária a transfusão de concentrado de hemácias em 9 pacientes (47,4\%), sendo que em 5 doentes foi necessária uma unidade e em 4 duas unidades. Em 52,6\% dos pacientes não foi necessária reposição de hemoderivados (Tabela 7). 
Tabela 7. Necessidade de transfusão de concentrado de hemácias durante a operação

\begin{tabular}{cccc}
\hline Unidades de & Concentrado de & \multicolumn{2}{c}{ Número de Pacientes } \\
\cline { 3 - 4 } Hemácias & & Absoluto & $\%$ \\
\hline 0 & 10 & 52,6 \\
1 & 5 & 26,3 \\
2 & 4 & 21,1 \\
& Total & 19 & 100,0
\end{tabular}

\section{6 - Tempo operatório}

O tempo operatório médio foi de 282,1 minutos, variando de 255 a 360 minutos.

\section{7 - Complicações pós-operatórias}

As complicações decorrentes do ato operatório ocorreram em $36,8 \%$ dos pacientes e foram: íleo adinâmico em 5 pacientes (26,3 \%); isquemia mesentérica em 2 pacientes (10,5\%); trombose parcial da veia porta em 1 paciente $(5,2 \%)$ e trombose total da veia porta em 1; infecção do trato urinário em 1 paciente $(5,2 \%)$; abscesso subfrênico em 1 paciente (5,2\%); e 1 caso de necrose de fundo gástrico (5,2\%), conforme demonstrado na Tabela 8.

Nenhuma complicação pós-operatória teve relação com a cateterização do ramo jejunal e colocação cateter no interior da veia porta. 
Tabela 8. Complicações pós-operatórias após desconexão ázigo-portal mais esplenectomia em pacientes com esquistossomose forma hepato-esplênica.

\begin{tabular}{lcc}
\hline Complicação & Número de pacientes & $\%$ \\
\hline Íleo adinâmico & 5 & 26,3 \\
Isquemia mesentérica & 2 & 10,5 \\
Trombose de veia porta & 2 & 10,5 \\
CIVD & 1 & 5,2 \\
Infecção do trato urinário & 1 & 5,2 \\
Abscesso subfrênico & 1 & 5,2 \\
Necrose gástrica & 1 & 5,2 \\
\hline
\end{tabular}

\section{8 - Mortalidade operatória / pós-operatória}

Não houve mortalidade intra-operatória.

Três pacientes (15,7\%) evoluíram a óbito no período pós-operatório: um por septicemia secundária a pneumonia no $60^{\circ}$ pós-operatório; um por coagulação intravascular disseminada (CIVD), secundária a um grande coágulo intraperitoneal no $5^{\circ}$ pós-operatório e outro por septicemia após perfuração da transição corpo/fundo gástrico por necrose isquêmica no $13^{\circ}$ pós-operatório. 


\section{9 - Reoperações}

Em quatro pacientes foi necessária reoperação. Em dois a reintervenção deveu-se a trombose mesentérica, sendo que em um esta localizava-se em pequeno segmento de jejuno, no $75^{\circ}$ pós-operatório. Realizou-se a enterectomia e reconstrução do trânsito com boa evolução. O segundo paciente evoluiu com necrose intestinal de grande segmento do jejuno e íleo, no $20^{\circ}$ pós-operatório, sendo realizada enterectomia e reconstrução do trânsito. Na sua evolução apresentou fístula entérica, evoluindo para óbito por septicemia devido a pneumonia no $60^{\circ}$ pós-operatório. Um paciente apresentou necrose isquêmica na transição corpo-fundo do estômago com perfuração, tendo sido reoperado no $5^{\circ}$ pós-operatório, sendo realizado debridamento da área necrosada e gastrorrafia, evoluiu com septicemia por peritonite e óbito no $8^{\circ}$ pós-operatório da reoperação. Um paciente apresentou abscesso subfrênico, sendo reoperado no $32^{\circ}$ pósoperatório e realizada a drenagem, tendo apresentado boa evolução (Tabelas 9 e 10). 
Tabela 9. Tratamento e evolução das complicações pós-opertórias.

\begin{tabular}{|c|c|c|c|}
\hline Complicação & No de pacientes & Tratamento & Evolução \\
\hline Íleo adinâmico & 5 & Clínico & Favorável \\
\hline $\begin{array}{c}\text { Isquemia } \\
\text { mesentérica }\end{array}$ & 1 & Cirúrgico & Favorável \\
\hline $\begin{array}{c}\text { Isquemia } \\
\text { mesentérica } \\
+ \\
\text { trombose de veia } \\
\text { porta }\end{array}$ & 1 & Cirúrgico & Óbito \\
\hline $\begin{array}{c}\text { CIVD } \\
+ \\
\text { trombose v. porta }\end{array}$ & 1 & Clínico & Óbito \\
\hline Infecção urinária & 1 & Clínico & Favorável \\
\hline Abscesso sbfrênico & 1 & Cirúrgico & Favorável \\
\hline Necrose gástrica & 1 & Cirúrgico & Óbito \\
\hline
\end{tabular}


Tabela 10. Evolução dos pacientes submetidos a reoperação

\begin{tabular}{lcc} 
Complicação & Tratamento & Evolução \\
\hline $\begin{array}{l}\text { Trombose mesentérica + } \\
\text { isquemia intestinal }\end{array}$ & Enterectomia & Fístula / pneumonia / óbito \\
Isquemia mesentérica & Enterectomia & Favorável \\
Abscesso subfrênico & Drenagem cirúrgica & Favorável \\
Necrose gástrica & & Peritonite / septicemia / \\
\end{tabular}

\subsection{0 - Tempo de internação}

O tempo médio de internação foi de 13,1 dias, variando de 5 a 52 dias. Conforme observado na figura 3. 
Figura 3. Distribuição individual do tempo de internação.

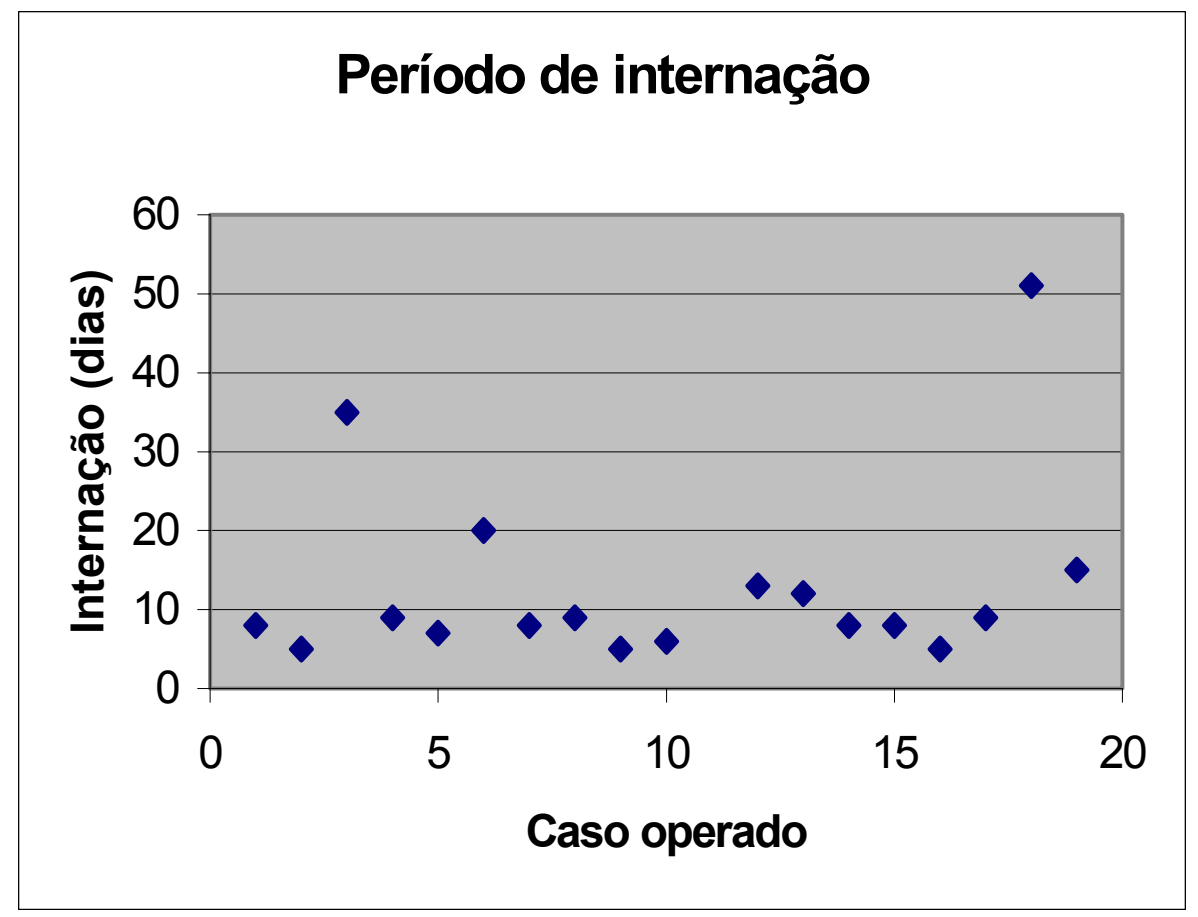

\subsection{1 - Acompanhamento ambulatorial}

O tempo médio de seguimento foi de 24,6 meses, variando entre 1 e 78 meses (figura 6). Dos dezesseis pacientes que tiveram alta hospitalar, quatorze tiveram seguimento de até de seis meses. Em doze pacientes o seguimento foi maior que seis meses. Destes em um caso observou-se hemorragia digestiva alta (8,3\%), devido a úlcera gástrica, sete meses após a desconexão ázigo-portal e esplenectomia. 
Nenhum paciente, durante o acompanhamento, apresentou ressangramento por ruptura de varizes esofágicas.

Todos os pacientes apresentavam-se assintomáticos e com avaliação laboratorial da função hepática normal durante sua evolução.

Figura 4. Distribuição individual do seguimento pós-operatório.

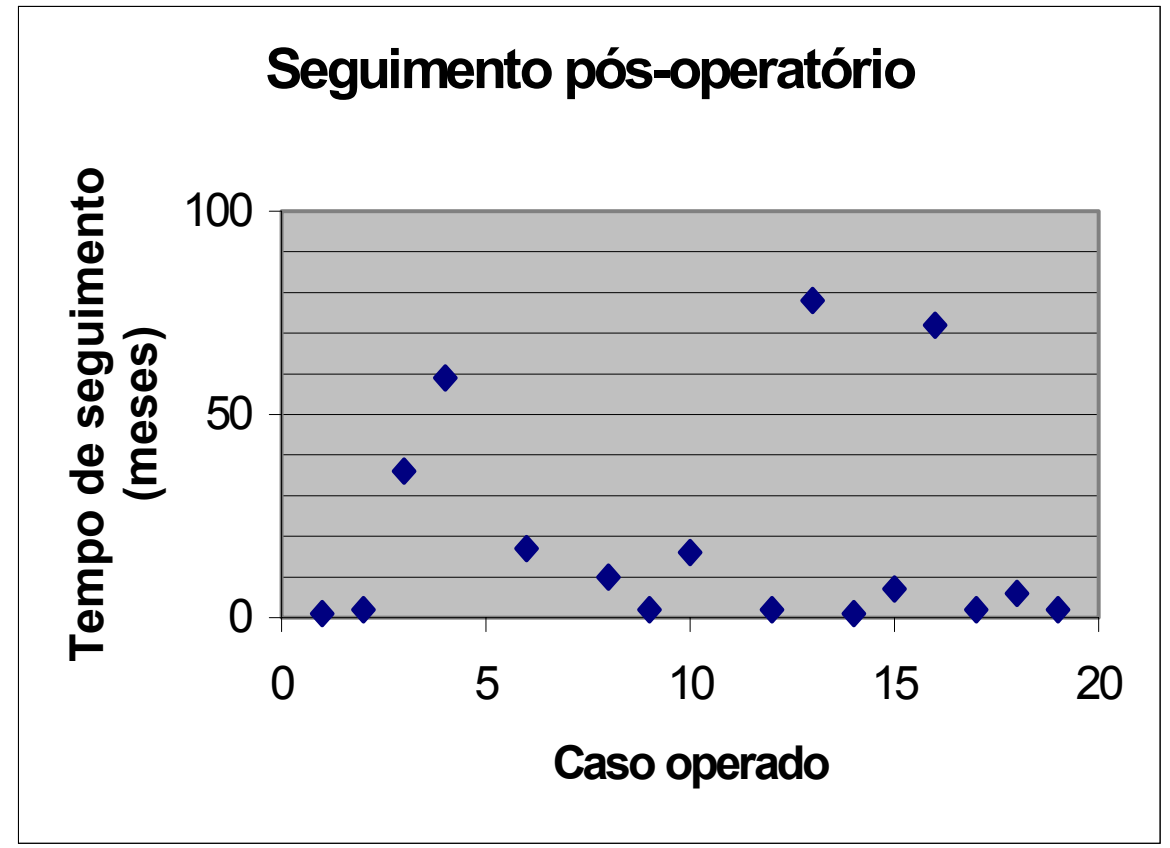

\subsection{2 - Avaliação endoscópica pós-operatória}

Dos 16 pacientes que tiveram alta hospitalar, $12(75 \%)$ foram submetidos a acompanhamento endoscópico e , quando necessário, esclerose endoscópica das varizes esofágicas, por período que variou de 6 a 78 meses com média de 28,3 meses. As varizes apresentaram regressão estatisticamente significativa no seu 
calibre quando comparados os períodos pré e pós-operatório, tanto imediato (primeira avaliação endoscópica 60 dias após a cirurgia) quanto tardio e também quando comparados os pós-operatórios imediato e tardio. Em dois casos, durante o programa de escleroterapia endoscópica, houve erradicação das varizes esofágicas (16,6\%). Como demonstrado nas Tabelas 11, 12 e 13 e na Figura 5.

Tabela 11. Comparação do calibre das varizes esofagianas nos períodos préoperatório e pós-operatório precoce (cerca de 60 dias)

\begin{tabular}{lcccc}
\hline \multirow{2}{*}{$\begin{array}{l}\text { Classificação das } \\
\text { varizes Segundo } \\
\text { Palmer }\end{array}$} & \multicolumn{2}{c}{ Pré-operatório } & \multicolumn{2}{c}{ Pós-operatório precoce } \\
\cline { 2 - 5 } & Número & $(\%)$ & Número & $(\%)$ \\
\hline 0 & - & $(0,0)$ & - & $(0,0)$ \\
I & 1 & $(5,3)$ & 6 & $(42,9)$ \\
II & 2 & $(10,5)$ & 6 & $(42,9)$ \\
III & 16 & $(84,2)$ & 2 & $(14,3)$ \\
Total & 19 & $(100,0)$ & 14 & $(100,0)$ \\
\hline
\end{tabular}

$\mathrm{P}=0,004$ 
Tabela 12. Comparação entre o calibre das varizes esofagianas nos períodos préoperatório e pós-operatório tardio

\begin{tabular}{lcrcr}
\hline \multirow{2}{*}{$\begin{array}{l}\text { Classificação das varizes } \\
\text { Segundo Palmer }\end{array}$} & \multicolumn{2}{l}{ Pré-operatório } & \multicolumn{2}{l}{ Nós-operatório tardio } \\
\cline { 2 - 5 } & \multicolumn{2}{l}{ Número } & $(\%)$ & $(\%)$ \\
\hline 0 & 1 & $(0,0)$ & 2 & $(16,7)$ \\
I & 2 & $(10,5)$ & 8 & $(66,7)$ \\
II & 16 & $(84,2)$ & 1 & $(8,3)$ \\
III & 19 & $(100,0)$ & 1 & $(8,3)$ \\
Total & & & 12 & $(100,0)$
\end{tabular}

$P=0,005$

Tabela 13. Comparação entre o calibre das varizes esofagianas no pós-operatório precoce e tardio

\begin{tabular}{lcccc}
\hline $\begin{array}{l}\text { Classificação das } \\
\text { varizes Segundo } \\
\text { Palmer }\end{array}$ & \multicolumn{2}{l}{ Pós-operatório precoce } & \multicolumn{2}{l}{ Pós-operatório tardio } \\
\cline { 2 - 5 } & Número & $(\%)$ & 2 & $(16,7)$ \\
\hline 0 & - & $(0,0)$ & 8 & $(66,7)$ \\
I & 6 & $(42,9)$ & 1 & $(8,3)$ \\
II & 6 & $(42,9)$ & 1 & $(8,3)$ \\
III & 2 & $(14,3)$ & 12 & $(100,0)$ \\
Total & 14 & $(100,0)$ & 12 & \\
\hline
\end{tabular}

$P=0,030$ 
Figura 5. Avaliação endoscópica do calibre das varizes esofágicas segundo classificação de Palmer nos períodos pré-operatório, pós-operatório imediato e tardio da desconexão ázigo-portal e esplenectomia

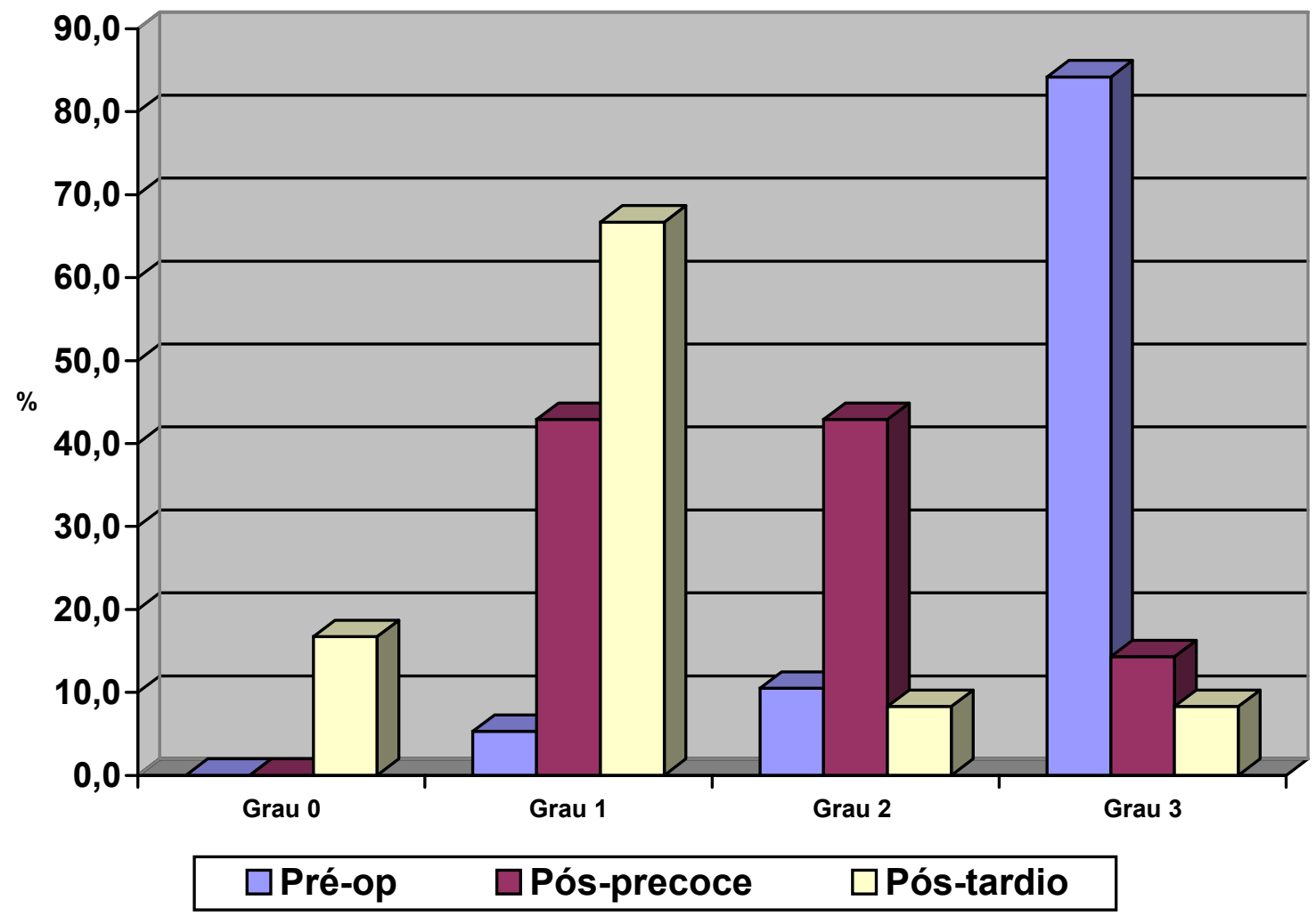




\section{5 - Discussão:}

Devido a sua grande incidência no Brasil, a esquistossomose mansônica representa patologia com forte impacto na saúde pública, com cerca de doze milhões de pessoas acometidas, sendo a sua forma hepato-esplênica a principal causa de hipertensão portal em nosso meio, atingindo um contingente de $10 \%$ dos acometidos por esta doença, ou seja, cerca de 1.200 .000 pessoas.

Dados da Organização Mundial de Saúde em relatório de 1990 calculam que a cada ano morrem 200 mil portadores de esquistossomose em todo o mundo, sendo o maior contingente no Brasil (LOPES FILHO et al., 1995). Levando-se em conta $o$ fato de a doença acometer predominantemente adolescentes e adultos jovens, com função hepática preservada, nota-se a dimensão da carga social que a doença exerce em nosso meio.

Como os portadores da doença apresentam uma função hepática preservada, a hemorragia digestiva alta causada por ruptura das varizes esofagianas representa a única causa de mortalidade para estes pacientes. Assim, um tratamento que fosse efetivo no controle do sangramento das varizes esofagianas traria um grande benefício para expectativa de vida destes doentes aumentando-a para níveis comparáveis aos da população geral (SAKAl et al., 1990). Este fato foi corroborado pela nossa casuística, onde os pacientes apresentavam idade média de 38 anos e exames laboratoriais de função hepática normais. Os pacientes aqui estudados, assim como observado por outros autores 
(POLLARA, 1992; PUGLIESI, 1996; FERRAZ et al., 1999), apresentavam apenas manifestação laboratorial do hiperesplenismo.

As alternativas terapêuticas hoje existentes são: 0 tratamento medicamentoso, o endoscópico, o cirúrgico ou a associação destes.

A droga mais estudada para a terapia medicamentosa da hipertensão portal foi o propanolol, um beta-bloqueador, inicialmente utilizado na França em pacientes cirróticos (LEBREC et al., 1984). Alguns autores analisaram sua ação em pacientes esquistossomóticos e encontraram resultados controversos, uns mostrando importante redução na pressão portal, em torno de 30\% (COELHO, 1987), já outros não evidenciaram redução na pressão portal, mas sim no fluxo sanguíneo na veia ázigos (MIES et al., 1997). Estes últimos sugeriram o seu emprego temporariamente até que 0 paciente pudesse ser submetido eletivamente ao tratamento cirúrgico (MIES et al., 1997). No entanto, o tratamento clínico não é isento de risco de mortalidade, como demonstrado em estudo realizado por CURY (1989), que acompanhou pacientes com esquistossomose forma hepato-esplênica em sua evolução natural (sem nenhum tipo de tratamento) com pelo menos um episódio de hemorragia digestiva e encontrou um índice de mortalidade em torno de $15 \%$. Ainda assim novas drogas têm surgido como alternativa, porém sem comprovada eficácia no tratamento definitivo da hemorragia por rotura de varizes esofagianas.

O tratamento endoscópico das varizes esofagianas quer por esclerose, quer por ligadura elástica, tem sido empregado como primeira escolha no tratamento de varizes esofagianas sangrantes (SAKAl et al., 1990; SAKAI, 2001). No entanto, o índice de recidiva hemorrágica deste método quando utilizado de forma isolada 
em pacientes com esquistossomose forma hepato-esplênica situa-se entre $11 \mathrm{e}$ 33,3\% (AL-KARAWI et al., 1986; EL-ZAYADI et al., 1988; MOHAMED et al., 1989; CURY, 1990; CORDEIRO, 1990; SAKAI et al., 1990; AL-KARAWI et al., 1996), tornando-o pouco recomendável como primeira e definitiva opção para o tratamento das varizes esofagianas nestes pacientes.

Os tratamentos clínico e endoscópico não satisfizeram as metas para o tratamento do sangramento por varizes esofagianas nos pacientes com esquistossomose mansônica forma hepato-esplênica, quais sejam: erradicar as varizes ou impedir a hemorragia digestiva alta, sem ou com poucos efeitos colaterais. Deste modo, tem-se buscado outras alternativas terapêuticas e a preferência tem sido pela abordagem cirúrgica.

O tratamento cirúrgico da hipertensão portal na esquistossomose hepatoesplênica, representa um consenso nos serviços com grande experiência nesta afecção (CARNEIRO, 1979; ABRANTES et al., 1983; PITANGA, 1986; KARARA et al., 1987; BOIN, 1991; CAPUA et al., 1992; PUGLIESI, 1996; FERRAZ, 2000; GAWISH, et al., 2000).

Existem duas cirurgias mais empregadas para o tratamento da hipertensão portal por esquistossomose hepato-esplênica, não havendo um consenso sobre o método cirúrgico ideal na abordagem destes pacientes. No Brasil, há autores que utilizam a derivação espleno-renal distal e os que advogam a desconexão ázigoportal e esplenectomia como melhor opção. A primeira apresenta um índice de ressangramento entre 3,3 e 8\% (PITANGA , 1986; EZZAT et al., 1990; RAIA et al., 1994; GAWISH et al., 2000; ABRANTES \& DRUMOND, 1995), porém com índices de encefalopatia porto-sistêmica, variando entre 3,3 e 14\% (SAAD et al., 
1977; PITANGA, 1986; CURY, 1990; EZZAT et al., 1990; ABRANTES, 1991; RAIA et al., 1994), grave complicação em um paciente previamente hígido. Já a cirurgia de desconexão não apresenta encefalopatia como complicação, no entanto, é acompanhada por uma taxa de ressangramento entre 6 e 50\% (HASSAB, 1967; EL MASRI \& HASSAN, 1982; KELNER, 1982; HADDAD et al., 1982; CHAIB et al., 1983; BESSA et al., 1988; EZZAT et al., 1990; RAIA et al., 1994; FERRAZ, 2000). Os significativos índices de ressangramento após cirurgias de desconexão podem ser diminuídos quando associadas à escleroterapia endoscópica pós-operatória (SAKAl et al., 1990).

Em 1978, RAIA, através de uma meta-análise demonstrou que $60 \%$ dos autores nacionais preferiam a desconexão ázigo-portal e esplenectomia como tratamento dos pacientes com esquistossomose hepato-esplênica e história de sangramento por rotura de varizes esofagianas, sendo que atualmente esta opção terapêutica é utilizada na grande maioria dos centros que tratam esta afecção (CARNEIRO, 1989; BOIM 1991; CAPUA et al., 1992; PUGLIESI, 1996; CLEVA, 1996; FERRAZ et al., 2001). Esta opção terapêutica também é utilizada em nosso Serviço, já que apresenta um índice satisfatório de controle do sangramento sem o inconveniente da encefalopatia porto-sistêmica que ocorre após a derivação portosistêmica seletiva (RAIA et al., 1971; RAIA et al., 1971; SAAD et al., 1977; EZZAT et al., 1986; PITANGA, 1986; CURY, 1990; EZZAT et al., 1990; SALAM et al., 1990; ABRANTES, 1991).

Devido aos resultados ainda insatisfatórios da desconexão ázigo-portal e esplenectomia quando utilizada de forma isolada no que se refere ao índice de ressangramento no tratamento da hipertensão portal na esquistossomose hepato- 
esplênica tem-se estudado a combinação de duas ou mais modalidades terapêuticas. Partindo desta premissa, uma opção seria a associação do tratamento cirúrgico com a esclerose endoscópica pós-operatória das varizes esofagianas, que segundo estudo realizado por SAKAl et al., em 1990, mostra uma queda significativa da recidiva hemorrágica quando comparada ao tratamento endoscópico isolado (2,7\% para o primeiro e $27,3 \%$ para o segundo). O mesmo autor em revisão recente (SAKAl, 2001), reforçou esta posição quando comparou pacientes esquistossomóticos submetidos a programa de escleroterapia, com e sem cirurgia prévia, e observou um controle definitivo do sangramento no primeiro grupo em $97 \%$ dos casos e no segundo grupo em $72 \%$, diferença esta estatisticamente significativa. Assim, a associação entre o tratamento cirúrgico como a desconexão ázigo-portal e esplenectomia e o tratamento endoscópico das varizes, representa uma boa alternativa no tratamento da hipertensão portal, uma vez que a abordagem endoscópica se fará em um vaso de menor calibre e com menor fluxo portal após a cirurgia. Esta associação terapêutica tem sido utilizada por vários autores em nosso meio (LEONARDI et al., 1988; BOIN, 1991; POLLARA, 1992; PUGLIESI, 1996) e vem sendo estudado em nosso Serviço.

Estudo recente demonstra que a desconexão ázigo-portal associada à esplenectomia levou à diminuição do calibre das varizes esofagianas em $72 \%$ dos pacientes (STRAUSS et al., 1999). Esta diminuição no calibre das varizes é consequência, provavelmente, da redução do fluxo portal que ocorre após a esplenectomia (CLEVA, 1996). O menor calibre das varizes esofagianas encontrados após a desconexão ázigo-portal e esplenectomia além de facilitar a escleroterapia endoscópica (SAKAl et al., 1990), também diminui a possibilidade 
de ressangramento e, se este ocorrer, terá menor intensidade e gravidade do que em pacientes com varizes de grosso calibre, como demonstrou CURRY, em 1989, que acompanhando pacientes esquistossomóticos forma hepato-esplênica encontrou correlação direta entre o maior calibre das varizes esofagianas e maior frequência e gravidade dos episódios de sangramento.

Assim, o resultado esperado para a desconexão ázigo-portal e esplenectomia em relação ao calibre das varizes esofagianas seria o desaparecimento dos cordões varicosos esofágicos. No nosso estudo, em apenas dois pacientes $(16,6 \%)$ houve o desaparecimento completo das varizes esofagianas, no entanto, o calibre destas apresentou regressão significativa após o tratamento cirúrgico, tanto na comparação feita entre os períodos pré-operatório e pós-operatório precoce, quanto na comparação tardia, feita entre 6 e 78 meses de pós-operatório quando associou-se a escleroterapia endoscópica. Outro resultado interessante no nosso estudo foi a diferença significativa quando comparou-se os resultados da avaliação endoscópica precoce com a tardia, o que confirma que a escleroterapia endoscópica influi favoravelmente na evolução do calibre das varizes a longo prazo. Este fato também foi observado em estudo realizado por CHAIB et al., em 1983, que encontraram $69,8 \%$. STRAUSS et al. em 1999 também encontraram redução do calibre das varizes esofagianas após a desconexão ázigo-portal e esplenectomia em $72 \%$ dos pacientes. Estudos realizados por FERRAZ et al., em 1999 e 2001 demonstraram aumento na proporção da erradicação do calibre das varizes de esôfago de 18,2\% para 52,7\% quando empregada a desconexão ázigo-portal e esplenectomia associada à esclerose endoscópica pós-operatória das varizes. Ainda analisando o calibre das 
varizes esofágicas após a desconexão ázigo-portal, PUGLIESI (1996), verificou desaparecimento dos cordões varicosos em dois terços dos pacientes que se submeteram a escleroterapia endoscópica pós-operatória.

Apesar de ser doença endêmica em nosso meio, a hemodinâmica portal nos doentes acometidos pela esquistossomose forma hepato-esplênica é pouco conhecida, assim, um melhor entendimento dos mecanismos fisiopatológicos da hemodinâmica portal e das repercussões que o tratamento cirúrgico traria a este sistema previamente hipertenso apresenta grande importância uma vez que poderá servir de subsídio para a determinação do melhor esquema terapêutico.

A escassez de estudos acerca das repercussões hemodinâmicas no sistema portal desencadeadas pela desconexão ázigo-portal e esplenectomia em pacientes esquistossomóticos gerou resultados controversos, não permitindo uma posição definitiva sobre o seu efeito no sistema portal.

Estas dúvidas, bem como os resultados divergentes de outros estudos nos estimularam a estudar, em nosso Serviço, o impacto do tratamento cirúrgico na hemodinâmica portal e em especial na pressão portal.

Um fator controverso em relação à desconexão ázigo-portal e esplenectomia é a repercussão sobre a pressão portal. Alguns autores têm estudado este assunto utilizando diversos meios para aferir a pressão portal, seja através de cateterização de veia mesentérica ou epiplóica, seja por punção do baço, do fígado ou de variz esofágica, ou ainda através de manômetro posicionado endoscopicamente ao nível das varizes esofagianas. Com o avanço tecnológico foi possível a avaliação não só da pressão, como também do fluxo 
portal por meio de cateter de termodiluição de SWAN-GANZ posicionado no interior da veia porta (CLEVA, 1996).

CARNEIRO em 1979, através de cataterização trans-hepática da veia porta, avaliou a pressão portal de pacientes submetidos a desconexão ázigo-portal com pelo menos 2 anos de pós-operatório, e encontrou valores próximos de $15 \mathrm{~mm} \mathrm{Hg}$ em pacientes que não apresentaram nenhum episódio de ressangramento, considerando assim que este valor representaria o limite protetor para a ocorrência de hemorragia. Já CLEVA em 1996, através de cateterização da veia porta com cateter de SWAN-GANZ e aferição da pressão, encontrou uma queda aproximada de $30 \%$ da pressão portal logo após a ligadura da artéria esplênica, pressão esta que se manteve estável até o final da desconexão ázigo-portal. Estes dados são referendados por trabalho realizado por POLLARA em 1992 que, ao cateterizar a veia porta através de uma veia jejunal, demonstrou queda de $25 \%$ nos níveis da pressão portal após a simples ligadura da artéria esplênica. Por outro lado estes resultados não foram reproduzidos por CAPUA Jr. et al., em 1992 e STELMACH e CAPUA Jr. em 1996, em avaliação da pressão portal utilizando cateter de polietileno introduzido na veia gastro-epiplóica direita e progredido até a veia porta, que demonstraram uma queda média de $20 \%$ após esplenectomia com elevação da pressão portal após a desvascularização da grande e pequena curvatura do estômago, até níveis pressóricos próximos dos iniciais. No nosso estudo, a diferença entre a pressão portal no início e ao final da desconexão ázigo-portal e esplenectomia foi de $31,3 \%$.

Estes estudos apresentam relevada importância uma vez que a pressão portal apresenta valores equivalentes à pressão ao nível das varizes esofagianas, 
conforme observado por MOSIMANN et al. em 1983. Este, utilizando um manômetro colocado em contato com as varizes esofágicas através de gastroscopia com aferição simultânea da pressão na veia porta através de cateterização de uma veia mesentérica em pacientes com hipertensão portal, demonstrou similaridade entre as pressões portais e das varizes. LACERDA et al. em estudo publicado em 1998, aferiram a pressão ao nível das varizes esofagianas com manômetro pneumático acoplado a endoscópio antes e após a esplenectomia e ligadura da veia gástrica esquerda em pacientes esquistossomóticos e encontraram uma queda altamente significativa da pressão das varizes $(28,5 \%)$ após o procedimento. Portanto, as variações de pressão encontradas após intervenções sobre o território portal são superponíveis as do território das varizes esofagianas evidenciando-se assim uma correlação direta entre a queda na pressão portal e o sucesso do tratamento.

A provável causa da queda na pressão portal após a desconexão ázigoportal e esplenectomia é a retirada da circulação esplênica do circuito sistêmicoportal como resultado da esplenectomia. Isto se deve, muito provavelmente, ao fluxo aumentado no território esplênico secundário à intensa esplenomegalia e ao fato do baço exercer um papel de grande fístula artério-venosa, levando a uma circulação sistêmica hiperdinâmica, com aumento do débito cardíaco e queda na resistência vascular periférica (CLEVA, 1996). O mesmo autor demonstrou que, a partir da ligadura da artéria esplênica, haveria interrupção desta circulação hiperdinâmica com consequente queda na pressão portal. Esta acertiva é corroborada neste mesmo estudo em que se demostrou uma queda de $28 \%$ do fluxo portal após a retirada do fluxo esplênico deste circuito (ligadura da artéria 
esplênica), além disto também se observou que tanto o fluxo quanto a pressão portal mantiveram-se estáveis após a esplenectomia e desvascularização esôfago-gástrica. POLLARA (1992), também demonstrou queda de $25 \%$ na pressão portal apenas com a ligadura da artéria esplênica.

Embora a cavidade abdominal aberta não reflita o real valor da pressão portal, nosso estudo mostrou queda da pressão portal média de $33 \mathrm{cmH} 2 \mathrm{O}$ para $22 \mathrm{cmH} 2 \mathrm{O}$ quando a pressão foi aferida no início e no final da operação, diferença esta estatisticamente significante. A possibilidade de que a queda na pressão portal se devesse à hipovolemia, foi descartada pela avaliação, sempre concomitante da pressão arterial média invasiva e da frequência cardíaca, que se mostraram estáveis, sem alteração estatisticamente significativa quando analisadas no início e final de todos os procedimentos. Além disso, a maioria dos pacientes não necessitou de transfusão sanguínea no ato operatório e, quando se fez necessário, foram utilizadas no máximo, duas unidades de concentrado de hemácias, com média de 0,8 unidades por paciente, devendo-se levar em conta que muitos pacientes apresentavam anemia no pré-operatório em decorrência de episódios de sangramento prévios e do hiperesplenismo.

Atualmente, em um modelo ideal, os parâmetros utilizados na avaliação hemodinâmica sistêmica devem incluir: pressão venosa central (PVC), frequência cardíaca, pressão arterial média invasiva, e monitorização invasiva de pressão da artéria pulmonar por cateter de termodiluição de SWAN-GANZ. No entanto, em nosso Serviço, devido à dificuldades estruturais, este cateter não se encontra disponível. Já a PVC, que não foi utilizada nos primeiros casos, após um maior entrosamento entre os Serviços de Cirurgia Geral e Anestesiologia, passou a ser 
utilizada de forma rotineira, tendo sido aferida nos dois últimos pacientes incluídos neste estudo.

Dois pacientes apresentaram trombose da veia porta confirmada após a realização de ultra-som doppler, representando um percentual de 10. Dados semelhantes aos encontrados na literatura onde se descrevem valores que variam entre 13,2 e 53,2\%. (PUGLIESI, 1996; FERRAZ, 2000). Esta complicação tem como causa provável a diminuição do fluxo sanguíneo na veia porta após a esplenectomia (queda de 28\%), a estagnação do sangue causada pela ligadura das colaterais (CLEVA,1996) e pelo aumento de plaquetas que se segue à esplenectomia nestes pacientes (CHAIB et al., 1996). A trombose portal talvez tenha sido subestimada em nosso estudo, uma vez que apenas os pacientes com sintomatologia foram submetidos à propedêutica diagnóstica.

A isquemia venosa mesentérica ocorreu em dois casos (10\%), uma delas acometeu pequeno segmento jejunal e evoluiu favoravelmente após ressecção intestinal. Já em outro caso em que a trombose venosa mesentérica, que estava associada à trombose da veia porta a paciente evoluiu desfavoravelmente com fístula, peritonite, septicemia e óbito. A trombose mesentérica após a desconexão ázigo-portal e esplenectomia também foi demonstrada por CHAIB et al., em 1996, em relato de três casos, em que dois evoluíram bem com medidas de suporte clínico e um necessitou de seguidos procedimentos de ressecção intestinal, culminando com o óbito. Os mecanismos que levariam a esta trombose ainda não estão bem esclarecidos, porém como já citamos, dois fatores predisponentes à trombose venosa estão presentes: a estase venosa e a trombocitose que acontecem após a retirada do baço e podem ser lembrados como possíveis 
precipitadores tanto para a trombose ao nível da veia porta, como sua extensão para o tronco mesentérico.

A mortalidade operatória ocorreu em $15,7 \%$ dos pacientes (3 casos). Um por CIVD secundária a coagulopatia de consumo por coágulos intra-abdominais, um por peritonite e septicemia desencadeada por necrose do fundo gástrico e outro por septicemia secundária a fístula após ressecção intestinal. Outros estudos observaram uma taxa de mortalidade que variou entre 5,3 e $13,6 \%$ (HADDAD et al., 1981; RANGEL et al., 1990; BOIN, 1991; FERRAZ et al., 2001), o que demonstra que embora a desconexão ázigo-portal e esplenectomia seja um procedimento técnico facilmente exequível, não requerendo aparentemente nem de material, nem de treinamento especializados, apresenta risco de complicações graves. Estes resultados destoam dos encontrados por POLLARA (1992) e PUGLIESI (1996), que não tiveram óbitos em suas casuísticas. Ainda assim, devese ressaltar que embora a desconexão ázigo-portal e esplenectomia, seja cirurgia de relativa facilidade técnica, está associada a complicações potencialmente letais e esta possibilidade não deve ser desprezada durante a programação do ato operatório, ficando patente que este procedimento deve ser realizado em centros médicos especializados com cirurgiões experientes e com suporte técnico intra e pós-operatório adequado.

Dos dezesseis pacientes acompanhados ambulatorialmente, doze $(75 \%)$ tiveram seguimento endoscópico associado a escleroterapia quando necessário por um período que variou entre 6 e 78 meses. Sangramento por úlcera gástrica foi observado em 1 paciente 10 meses após a operação $(8,3 \%)$ e nenhum paciente apresentou recidiva hemorrágica pelas varizes esofágicas. Os índices de 
ressangramento encontrados na literatura variam entre 5,1 e 14,4\% (SAKAl et al., 1990; BOIN, 1991; PUGLIESI, 1996; FERRAZ, 2000). Cabe ressaltar que embora os valores de ressangramento após desconexão ázigo-portal e esplenectomia encontrados na literatura sejam considerados relevantes, a intensidade destes episódios, em sua maioria é de leve intensidade e de fácil controle endoscópico. Nenhum destes autores acima citados refere mortalidade nos episódios de ressangramento. Além disso, a escleroterapia endoscópica em pacientes submetidos a desconexão ázigo-portal e esplenectomia é mais efetiva que em pacientes sem cirurgia prévia (SAKAl, 2001), já que os vasos se apresentam com menor calibre, facilitando a ação do endoscopista. Isto talvez se deva ao fato de que a queda de pressão portal após a desconexão ázigo-portal mais esplenectomia demonstrada por alguns autores (POLLARA, 1992; CLEVA, 1996), é transferida para os vasos esofágicos, uma vez que as alterações na pressão portal apresentam valores equivalentes às da pressão ao nível das varizes esofágicas (MOSIMANN et al., 1983). Portanto, as variações de pressão encontradas após intervenções sobre o território portal são superponíveis as do território das varizes esofágicas evidenciando-se assim uma correlação direta entre a queda na pressão portal e o sucesso do tratamento.

O tratamento cirúrgico ainda se apresenta como a melhor opção terapêutica para pacientes com esquistossomose forma hepato-esplênica com história de hemorragia por rotura de varizes esofagianas. Dentre as cirurgias propostas a desconexão ázigo-portal mais esplenectomia é a mais aceita em nosso meio, no entanto apresenta altos índices de morbidade, recidiva hemorrágica entre 5 e 10\% e taxas de mortalidade que podem superar os $10 \%$. Estes dados não podem 
credenciá-la como única escolha no tratamento destes pacientes. Os índices de ressangramento apresentam uma queda substancial quando se associa à desconexão ázigo-portal e esplenectomia a escleroterapia endoscópica pósoperatória, o que a nosso ver deve ser obrigatório. É provável que a queda na pressão portal verificada neste trabalho e por outros autores após a desconexão ázigo-portal e esplenectomia, com consequente repercussão para o sítio das varizes esofagianas explique os bons resultados deste procedimento no tratamento de pacientes com esquistossomose forma hepato-esplênica. 


\section{6 - Conclusões}

1. A desconexão ázigo-portal e esplenectomia promoveu queda imediata da pressão portal em pacientes com esquistossomose forma hepato-esplênica.

2. A desconexão ázigo-portal e esplenectomia foi eficaz no tratamento de pacientes com hipertensão portal e hemorragia digestiva alta por rotura de varizes esofagianas por esquistossomose na forma hepato-esplênica. 


\section{ANEXO 1}

Resultado dos exames bioquímicos pré-operatórios:

\begin{tabular}{cccccccc}
\hline Caso & Albumina & TAP & TGP & TGO & BT & BD & Fosfatase \\
\hline 1 & 4,0 & 87 & 24 & 28 & 0,8 & 0,5 & 239 \\
2 & 4,0 & 86 & 25 & 28 & 0,8 & 0,4 & 237 \\
3 & 4,4 & 80 & 10 & 21 & 0,8 & 0,4 & 427 \\
4 & 3,7 & 93 & 43 & 45 & 1,2 & 0,8 & 437 \\
5 & 4,0 & 86 & 25 & 27 & 0,8 & 0,4 & 238 \\
6 & 3,6 & 87 & 16 & 14 & 0,5 & 0,2 & 179 \\
7 & 4,8 & 100 & 18 & 20 & 0,4 & 0,2 & 217 \\
8 & 4,2 & 75 & 47 & 48 & 0,9 & 0,4 & 265 \\
9 & 3,5 & 80 & 21 & 25 & 0,8 & 0,2 & 235 \\
10 & 4,0 & 87 & 24 & 27 & 0,8 & 0,5 & 237 \\
11 & 4,0 & 86 & 24 & 28 & 0,8 & 0,5 & 239 \\
12 & 3,8 & 91 & 23 & 26 & 0,8 & 0,6 & 242 \\
13 & 4,0 & 87 & 25 & 27 & 0,8 & 0,4 & 238 \\
14 & 4,0 & 87 & 24 & 28 & 0,8 & 0,5 & 237 \\
15 & 4,0 & 92 & 18 & 25 & 0,6 & 0,4 & 175 \\
16 & 3,7 & 75 & 27 & 23 & 1,2 & 0,8 & 123 \\
17 & 4,2 & 91 & 24 & 36 & 0,8 & 0,5 & 156 \\
18 & 4,0 & 86 & 24 & 28 & 0,8 & 0,5 & 239 \\
19 & 4,8 & 87 & 20 & 22 & 0,8 & 0,4 & 162 \\
\hline & & & & & & & \\
\hline
\end{tabular}


ANEXO 2

Evolução do calibre das varizes esofagianas:

(PALMER 1956)

\begin{tabular}{ccccc}
\hline Caso & Seguimento & Cal. Pré. & Cal. Pós prec. & Cal. Pós tard. \\
\hline 1 & 1 & 3 & - & - \\
2 & 2 & 3 & 1 & - \\
3 & 36 & 2 & 2 & 3 \\
4 & 59 & 3 & 2 & 1 \\
5 & 1 & 3 & - & - \\
6 & 17 & 3 & 1 & 0 \\
7 & 22 & 3 & 1 & 1 \\
8 & 10 & 2 & 1 & 1 \\
9 & 2 & 3 & 1 & - \\
10 & 17 & 3 & 3 & 1 \\
11 & - & 3 & - & - \\
12 & 2 & 3 & 3 & 1 \\
13 & 78 & 3 & 2 & 0 \\
14 & 36 & 1 & 1 & 1 \\
15 & 7 & 3 & 2 & 1 \\
16 & 72 & 3 & 2 & - \\
17 & - & 3 & - & 2 \\
18 & 6 & 3 & 2 & - \\
19 & 1 & 3 & - & \\
\hline
\end{tabular}


Complicações e evolução dos pacientes no seguimento pós-operatório

\begin{tabular}{ccccc}
\hline Caso & Seguimento & Tempo int. (dias) & Complicações & Evolução \\
\hline 1 & 1 & 8 & - & - \\
2 & 2 & 5 & Isquemia int. & fístula / óbito \\
3 & 36 & 35 & Íleo adinâmico & favorável \\
4 & 59 & 9 & não & favorável \\
5 & 1 & 7 & - & - \\
6 & 17 & 20 & Íleo adinâmico & favorável \\
7 & 22 & 8 & não & favorável \\
8 & 10 & 8 & Isq. int./ Trom. v.p. favorável \\
9 & 2 & 5 & não & favorável \\
10 & 17 & 6 & não & favorável \\
11 & - & óbito $1^{\text {a }}$ int. & CIVD & óbito \\
12 & 2 & 13 & Íleo adinâmico & favorável \\
13 & 78 & 12 & Íleo adinâmico & favorável \\
14 & 36 & 8 & não & favorável \\
15 & 7 & 8 & não & favorável \\
16 & 72 & 5 & ITU & favorável \\
17 & - & óbito $1^{\text {a }}$ int. & necrose f. gást. & óbito \\
18 & 6 & 52 & absc. sub. frên. & favorável \\
19 & 2 & 15 & Íleo adinâmico & favorável \\
\hline
\end{tabular}




\section{Bibliografia}

ABRANTES, W.L.; CARVALHO, M.A.; RABELO, G.D.; DRUMOND, D.A.F. Anastomose esplenorenal seletiva profilática na forma hepatesplênica da esquistossomose: experiência de 74 casos. Rev. Assoc. Med. Bras., v.29, n p.160-2, 1983.

ABRANTES, W. L. Hipertensão portal. In: DANI, R.; CASTRO, L. P. eds. Gastroenterologia Clínica. Rio de Janeiro, Guanabara Koogan, 1988, p.9831000.

ABRANTES, W.L. As derivações venosas no tratamento das varizes do esôfago. In: LEONARDI, L.S. ed Controvérsias na Cirurgia do Aparelho Digestivo. Rio de Janeiro, Medsi, 1991, p.283-92.

ABRANTES, W.L.; DRUMOND, D.A.F. Anastomose esplenorenal distal em esquistossomótico. Revisão de 200 pacientes operados há 11 e 22 anos. Clínica Bras. Cirurgia, v.1, p.243-54, 1995.

AL KARAWI, M. A.; MOHAMED, A. E.; HANID, M. A.; AL-OTAIBI, R.; SHAMED, $M$. Favourable outcome in sclerotherapy for bleeding oesophageal varices in schistosomiasis: results in 30 patients. J. Gastroenterol. Hepatology, v.1, p.151-7, 1986.

AL KARAWI, M. A.; MOHAMED, A. R. E. S.; AHMED, A. M. M.; SHARIQ, S.; YASAWY, M. I. Longterm outcome of endoscopic sclerotherapy of variceal bleeding: comparative study between schistosomiasis na others. HepatoGastroenterology, v.43, p.287-91, 1996.

AZEVEDO, R..; ALMEIDA, C.; ALMEIDA S.; COUTINHO, A. Estudo do fluxo sanguíneo arterial e portal em pacientes com esquistossomose mansônica. In: Anais do X CONGRESSO BRASILEIRO DE HEPATOLOGIA, Belo Horizonte, 1988.

BARSOUM, M.S.; BOLOUS, F.I.; ALY, A.M.H.; SAAD, M.; SOLIMAN, M.A.; DOSS, W.H.; ZAKARIA, S.; THAKEB, F. Acute variceal hemorrage: the persistent bleeder. A plea for management. World J. Sug., v.18, p.273-8, 1994. 
BESSA, S.M.; HELMY, I; Injection sclerotherapy for esophageal varices caused by schistosomal hepatic fibrosis. Surgery, v.97, p.164-8, 1984.

BESSA, S.M.; HELMY, I.; EL-SHEIK, S.O.; HAMAN, S.M.; EL-KISHEN, M.A. The distal splenorenal shunt in patients with variceal bleeding due to schistossomal hepatic fibrosis. Surg. Gynecol. Obstet., v.165, p.143-7, 1987.

BESSA, S.M.; HELMY, I.; HAMAN, S.M. \& EL-KAYAL, E.A. Esophageal transection by the EEA stapler for bleeding esophageal varices in schistosomal hepatic fibrosis. Surg. Gynecol. Obstet., v.166, p.17-22, 1988.

BOIN, I.F.S.F. Desvascularização Esofagogástrica ampla associada à Esplenectomia e Escleroterapia Programada no Pós-operatório no Tratamento das Varizes Esofagogástricas na Esquistossomose Hepatoesplênica. Campinas, 1991. Dissertação (Mestrado). Faculdade de Ciências Médicas da Universidade Estadual de Campinas.

BRUNO, M.A.; KREMER, A.; RODRIGUEZ FERRARI, C.; FRANCESE, P. \& MOGUILLANSDY, P. Control de la presion portal por metodos transhepaticos. Medicina, v.43, p.398-402, 1983.

CAPUA Jr., A.; SZUTAN, L. A.; SAAD Jr., R.; STELMACH, D.; ASSEF, J. C. Alterações da pressão porta de doentes esquistossomóticos submetidos à operação de esplenectomia e desconexão ázigo-portal. GED, v.11, n.1, 1992.

CARNEIRO, J.L.A. A Circulação Colateral Gastresofágica após Desconexão Ázigo-Portal. Portografia Trans-Hepática na Esquistossomose Mansônica. Vitória, 1979. Tese (Livre-Docência). Centro Biomédico da Universidade Federal do Espírito Santo. CARNEIRO 89

CHAIB, S.A.; LESSA, B.S.; CECCONELLO, I.; FELIX, V.N.; CHAIB, E. A new procedure for the treatment of bleeding esophageal varices by transgastric azigo-portal disconnection. Int. Surg., v.68, p.353-6 1983.

CHAIB, E.; HERMAN, P.; D'ALBUQUERQUE, L.C.; PUGLIESI, V.; ANTÔNIO, L.G.M.; FEIJÓ, L.F.A.; ISHIDA, R.Y.; SAAD, W.A.; PINOTTI, H.W. Trombose mesentérica após a desconexão ázigo-portal com esplenectomia para o tratamento das varizes esofageanas sangrantes na esquistossomose mansônica, relato de três casos. Rev. Hosp. Clín. Fac. Med. S. Paulo, v.51, p.65-8, 1996. 
CLEVA, R. Hemodinâmica Sistêmica e Portal em Doentes Esquistossomóticos, Forma Hepatoesplênica, Submetidos à Desconexão Ázigo-Portal, com Esplenectomia (DAPE). São Paulo, 1996. Tese (Doutorado). Faculdade de Medicina da Universidade de São Paulo.

CLEVA, R.; PUGLIESI, V.; ZILBERSTEIN, B; SAAD, W. A.; PINOTTI, H. W.; LAUDANNA, A. A. Estado hiperdinâmico sistêmico na forma hepatoesplênica da equistossomose mansônica. Rev. Hosp. Clín. Fac. Med. S. Paulo, v. 53, p.6-10, 1998.

COELHO, J.L. Propanolol em Portadores de Hipertensão Portal Esquistossomótica (Estudos Hemodinâmicos). São Paulo, 1987. Tese (Doutorado) Faculdade de Medicina da Universidade de São Paulo.

CORDEIRO, F. Variceal sclerosis in schistosomotic patients: a five-year follow-up study. Gastrointest. Endosc., v.36, p.475-8, 1990

CORNET, L.; N'GUESSAN, H.A.; MOBIOT, M.; LATOUCHE, J.C.; SHAUB,V.; MANZAN, K. Le traitment chirurgical de l'hypertension portale bilharzienne. Med. Trop. (Mars.), v.40, p.285-92, 1980.

COUTINHO, A.D.; DOMINGUES, A.L.C. Esquistossomose mansoni. In: DANI, R.; CASTRO, L.P. eds. Gastroenterologia Clínica. Rio de Janeiro, Guanabara Koogan, 1988, p.1361-86.

COURA, J.R.; QUEIROZ, G.C.; FLORÊNCIO, C.G.; ARGENTO, C.A.; COUTINHO, S.G.; FIGUEIREDO, N.; WANKE, B.; AMILLO-COURA, L. Morbidade da esquistossomose no Brasil. I. Estudo de 4652 casos osbservados no Rio de Janeiro de 1960 a 1979. Mem. Inst. Oswaldo Cruz, v.77, p.69-88, 1982.

CURY, A.A. Hepato-splenic form of the schistosomiasis: contributions to the natural history. Rev. Col. Bras. Cir., v.16, p.117-21, 1989.

CURRY, A. A. Anastomose espleno-renal distal seletiva versus esclerose endoscópica para o controle das varizes esofagianas em pacientes portadores de esquistossomose. Rev. Col. Bras. Cir., v.17, p.106-9, 1990. 
DANTAS, O.M. Manometria intra-esplênica transparietal. Sua aplicação na síndrome de hipertensão porta. Rev. Paul. Med., v.45, p.389-94, 1954.

De COCK, K.M. Splenomegaly and portal hypertention in Nairobi, Kenya: a study in geographical medicine. Bristol, 1983. Thesis (M.D.) - University of Bristol.

EL MASRI, S.H.; HASSAN, M.A. Splenectomy and vasoligation for patients with haematemesis secondary to bilharzial hepatic fibrosis. Br. J. Surg., v.69, p.3146, 1982.

EL ZAYADI, A.; EL-DIN, S.S.; KABIL, S.M. Endoscopic scleroterapy versus medical treatment for bleeding esophageal varices in patients with schistosomal liver disease. Gastrointest. Endosc., v.34, p.314-7, 1988.

EZZAT, F.A.; ABU-ELMAGD, K.M.; ALY, I.Y.; ALY, M.A.; FATHY, O.M.; ELBARBARY, M.H.; BAHGAT, O.O.; SALAM, A. a; KUTNER, M.H. Distal splenorenal shunt for management of variceal bleeding in patients with schistosomal hepatic fibrosis. Ann. Surg., v.204, p.566-73, 1986.

EZZAT, F. A.; ABU-ELMAGD, K. M.; ALY, M. A.; FATHY, O. M.; EL-GHAWLBY, N. A.; EL-FIKY, A. M.; EL-BARBARY, M. H. Selective shunt versus nonshunt surgery for management of both schisossomal and nonschistosomal variceal bleeders. Ann. Surg., v.212, p.97-108, 1990.

FERRAZ, A.A.B.; LOPES, E.P.A.; BACELAR, T.S.; SILVEIRA, M.J.C.; SILVA, L.M.M.; FERRAZ, E.M. Tratamento cirúrgico da hipertensão portal esquistossomótica no HC/UFPE - Análise de 131 casos. Rev. Col. Bras. Cir., v.27, n.5, 1999.

FERRAZ, A. A. B. Tratamento cirúrgico da hipertensão porta esquistossomótica na UFPE: aspectos históricos e contemporâneos. An. Fac. Med. Univ. Fed. Pernamb., v.45, p.153-4, 2000.

FERRAZ, A. A. B.; BACELAR, T. S.; MARCELLO, J. C. S.; COELHO, A. R. B.; CÂMARA NETO, R. D.; ARAÚJO JR., J. G. C.; FERRAZ, E. M. Surgical treatment of achistosomal portal hypertension. Int Surg., v.86, p.1-8, 2001. 
GAWISH, Y.; EL-HAMMADI, H.A.; KOTB, M.; AWAD, A.T.; ANWAR, M. Devascularization procedure and DSRS: a controlled randomized trial on selected haemodynamic portal flow pattern in schistosomal portal hypertension with variceal bleeding. Int. Surg., v.85, p.325-30, 2000.

GRACE, N. D.; MUENCH, H. and CHALMERS, T. C. The present status of shunt for portal hypertension in cirrhosis. Gastroenterology., v.50, p.684-91, 1966.

GUIMARÃES, J. S.; GOFFI, F. S. Estudo crítico sobre a anastomose esplenorrenal empregada no tratamento das hemorragias digestivas de esquistossomóticos. AMB Rev. Assoc. Med. Bras., v.19, p.501-6, 1973.

HADDAD, C.M.; PAN CHACON, J.; HERANI FILHO, B; KOBATA, C.; FIGUEIRA, A. Desvascularização gastroesofágica e esplenectomia no tratamento de varizes esôfago-gástricas. Rev. Col. Bras. Cir., v.8, n.6, 1981.

HADDAD, C. M.; PAN CHACON, J.; RICCA, A. B.; TOLEDO, L. F. Q. Desvascularização gastroesofágica e esplenectomia no tratamento da hemorragia aguda por varizes gastroesofágicas. Rev. Col. Bras. Cir., v.9, p.107-10, 1982.

HASSAB, M. A. Gastroesophageal decongestion and splenectomy in the treatment of esophageal varices in bilharzial cirrhosis: further studies with a report on 355 operations. Surgery, v.61, p.169-76, 1967.

KARARA, K.; EL-GENDI, M.A.; GERTSCH, PH.; MOSIMANN, R. Portal pressure measurements before and after Hassab,s decongestion operation. A preliminary report. Int. Surg. v.72, p.141-3, 1987.

KELNER, S.; FERREIRA, P.R.; DANTAS, A.; LIMA FILHO, J.F.C.; SOUZA, A.P.; CARREIRO Jr., J.C.P.; FERRAZ, E.M.; SILVEIRA, M.; COÊLHO, A.R.B.; CÂMARA NETO, R.D.; DOMINGUES, L.A.W. Ligadura de varizes esôfagogastricas na hipertensão porta esquistossomótica: avaliação de 25 anos. Rev. Col. Bras. Cir., v.9, p.140-6, 1982.

KELNER, S. Avaliação crítica da cirurgia na hipertensão portal esquistossomótica. Mem. Inst. Oswaldo Cruz, v.87, p.357-68, 1992. 
LACERDA, C. M.; FREIRE, W.; MELO, P. S. V.; CARVALHO, G. L.; KIRZNER, C. $F$. Esplenectomia e ligadura da veia gástrica esquerda na esquistossomose mansônica: efeito sobre a pressão das varizes de esôfago aferida por técnica não invasiva. Rev. Col. Bras. Cir., v.26. p.15-19, 1998.

LAUDANA, A. A. Bromossulfaleína no estudo da função hepática: padronização de métodos e significado clínico. São Paulo, 1972. Tese (Livre-Docência), Faculdade de Medicina da Universidade de São Paulo.

LEBREC, D.; POYNARD, T.; BERNUAU, J.; BERNCOFF, E.; NOUEL, O.; CAPRON, J.P.; POUPON, R.; BOUVRY, M.; RUEFF, B.; BENHAMOU, J.P.; A randomized controlled study of propanolol for prevention of recurrent gastrointestinal bleeding in patients with cirrhosis: a final report. Hepatology, v.4, p.355-8, 1984.

LEMOS-TORRES, U.; DEGNI, M. Bases raionales de una nueva tecnica de desconexion radical acigos-portal para el tratamiento de la hypertension porta: operacion de Lemos-Torres-Degni. Pren. Med. Argent., v.53, p.604-19, 1966.

LEONARDI, L.S.; BOIN, I.F.S.F.; BRANDALISE, N.A.; ANDREOLLO, N.A.; CALLEJAS NETO, F.; ANDRADE, R.G.; PAREJA, J.C. Results of the azigoportal disconnection and splenectomy associated with scleroterapy in schistosomiasis. ABCD Arq. Bras. Cir. Dig., v.3, p.99-103, 1988.

LOPES FILHO, G. J.; CHIBLY M. H.; SCALABRINI, M.; SATO, N. Y.; RICCA, A. B. Tratamento da hipertensão portal de etiologia esquistossomótica. GED., v.14, n.3, 1995.

MAHDY, A.A.A. Surgical correction of portal hypertension caused by schistossomal hepatic fibrosis. J. Egypt. Med. Ass., v.61, p.633-5, 1978

MACHADO, P. A. Programa especial de controle da esquistossomose: o modelo. In: $\mathbf{6}^{\mathrm{a}}$ Conferência Nacional de Saúde. Brasília, DF, Ministério da Saúde, 1977 , p. 267-84.

MIES, S.; LARSSON, E.; MORI, T.; ROSA, P.; RAIA, S. O sistema porta e as Artérias hepática, esplênica e mesentérica superior na esquistossomose hepatesplênica. Estudo angiográfico. Rev. Hosp. Clin. Fac. Med. São Paulo, v.35, p.121-31, 1980. 
MIES, S. Hemodinâmica Sistémica e Hepática na Esquistossomose Mansônica: Ação do Propanolol. São Paulo, 1992. Tese (Livre-Docência). Faculdade de Medicina da Universidade de São Paulo.

MIES, S.; BRAGHIROLLI NETO, O.; BEER Jr., A.; BAÍA, C.E.S.; ALFIERI Jr., F.; PEREIRA, L.M.M.B.; SETTE, M.J.A.; RAIA, S. Systemic and hepatic hemodynamics in hepatosplenic manson's Schisosomiasis with and without propanolol. Digestive Diseases and Sciences, v.42, n.4, 1997.

MOHAMED, A.E.; AL-KARAWI, M.A.; AL-OTAIBI, R.; HANID, M.A. Results of sclerotherapy in 100 patients: comparison of the outcome between schistosomiasis and hepatitis B. Hepato-Gastroenterol., v.36, p.333-6, 1989.

MORALI, G. A.; BLENDIS, L. M. Splenomegaly in portal hypertension: causes and effects. In: OKUDA, K.; BENHAMOU, P-P. ed. Portal hypertension: clinical and physiological aspects. Tokio, Springer-Verlag, 1991, p.85-99.

MORGAN, J.S.; GROSZMANN, R.J.; ROJKIND, M.; ENRIQUEZ, R. Hemodynamic mechanisms of emerging portal hypertension caused by schistosomiasis in the hamster. Hepatology, v.11, p.98-104, 1990.

MORIYASU, F. The principle of Doppler ultrasound. In: OKUDA, K.; BENHAMOU, J-P., ed. Portal hypertension: clinical and physiological aspects. Tokio, Springer-Verlag, 1991. p.151-9.

MOSSIMANN, R. Nonagressive assesment of portal hypertension using endoscopic measurement of variceal pressure. Preliminary report. Amer. J. Surg., v.143, p.212-14. 1982.

MOSIMANN, R.; BOHNET, J.; GARTSCH, Ph. Endoscopic non-agressive assessment of oesophageal variceal pressure compared with wedged hepatic venous pressure in alcoholic liver cirrhosis. Endoscopy, v.15, p.101-103, 1983.

OBEID, F.N.; SMITH, R.F.; ELLIOTT Jr., J.P.; REDDY, D.J.; HAGEMAN, J.H. Bilharzial portal hypertension. Arch. Surg., v.118, p.702-8, 1983.

OKUMURA, M. Contribuições para o Estudo do Tratamento Cirúrgico da Hipertensão Portal. São Paulo, 1967. Tese (Livre-Docência) Faculdade de Medicina da Universidade de São Paulo. 
PALMER, E. D. \& BRICKS, I. B. Correlation between the severity of esophageal varices in cirrhosis and their propensity toward hemorrage. Gastroenterology, v.30, p.85-90, 1956.

PATON, A.; REYNOLDS, T.B. \& SHERLOCK, S. Assessment of portal venous hypertension by catheterisation of hepatic vein. Original Articles, v.9, p.91821, 1953

PITANGA, L. C. Selective splenorenal anastomosis technical details and results of 340 patients subjected in 15 years. Dig. Dis. Sci., v. 31, p. 398S, 1986.

POLLARA, W. M. Desvascularização Esôfago-Gástrica por via Transmediastinal sem Esplenectomia no Tratamento das Varizes do Esôfago. Avaliação Clínica. São Paulo, 1992 Tese (Livre-Docência) Faculdade de Medicina da Universidade de São Paulo.

PRATA, A. Infection with S. mansoni . In: JORDAN, P.; WEBBE, G. eds. Schistosomiasis: Epidemiology, Treatment a Control. London, William Heinemann, 1982, p.105-27.

PRATA, A. Esquistossomose. In: AMATTO NETO, V.; BALDY, J.L.S. ed. Doenças Transmissíveis. São Paulo, Sardier, 1989, p.383-93.

PUGLIESI, V; MACHADO, M.C.C.; PINOTTI, H.W. Hipertensão portal. In: PINOTTI, H.W. ed. Tratado de Clínica Cirúrgica do Aparelho Digestivo. São Paulo, Atheneu, 1994, p.830-51.

PUGLIESI, V.; HERMAN, P.; COELHO, A. M.; KUBRUSLY, M. S.; SAMPIETRE, S. N.; MACHADO, M. C. C.; PINOTTI, H. W. Total hepatic blood flow in hepatosplenic schistosomiasis. In: EUROPEAN I.H.P.B.A. CONGRESS, Athens, 1995. Proceedings. Athens, Monduzzi, 1995. p.433-7.

PUGLIESI, V. Desconexão Ázigo-Portal e Esplenectomia Associados à Escleroterapia Endoscópica no Tratamento das Varizes do Esôfago na Esquistossomose Hepato-Esplênica: Avaliação de Parâmetros Clínicos, Laboratoriais e Hemodinâmicos Portais. São Paulo, 1996 Tese

(Doutorado) Faculdade de Medicina da Universidade de São Paulo. 
RAIA, S.; SILVA, A.T.; LOPES, J.D.; MIES, S.; OLIVEIRA, E. SILVA, A.; STRAUSS, E.; LAUDANNA, A.; RAIA, A.; SILVA, L.C. Descompressão portal seletiva por anastomose eplenorrenal distal para tratamento das varizes sangrantes do esôfago na esquistossomose mansônica. Rev. Hosp. Clín. Fac. Med. S. Paulo, v.26, p.149-52, 1971.

RAIA, S. Descompressão Portal Seletiva na Esquistossomose Mansônica. São Paulo, 1978. Tese (Livre-Docência) Faculdade de Medicina da Universidade de São Paulo.

RAIA, S. Portal hypertension in schistosomiasis. In: ORLOFF, M. J.; STIPA, S.; ZIPARO, V., ed. Medical and surgical problems of portal hypertension. London, Academic Press, 1980. p.301-12.

RAIA, S.; MIES, S.; ALFIERI Jr., F. Portal Hypertension in Mansonic Schistosomiasis. World J. Surg., v.15, p.176-87, 1991.

RAIA, S.; SILVA, L. C.; GAYOTTO, L. C. C.; FORSTER, S. C.; FUKUSHIMA, J.; STRAUSS, E. Portal hypertension in schistossomiasis: a long-term follow-up of a randomized trial comparing three types of surgery. Hepatology., v.20, p.398403, 1994.

RANGEL, M. F.; NÓBREGA, P. R. D.; CUNHA, G. A.; MENDES, J. L.; SOUZA, E. S.S.; SILVA, M. D. N.; SANTOS, I. T. B. Tratamento Cirúrgico da Hipertensão Portal Esquistossomótica. RUM., v.II, n.15, 1990.

REYNOLDS, T.B. Portal hypertension. In: SCHIFF, L.; SCHIFF, E.R.; ed. Diseases of the liver. Philadelphia, Lippincott, 1982. P.405-7.

ROCHA, P. Resultados Imediatos da Anastomose Porto-Cava Direta em Pacientes com Síndrome de Hipertensão Portal por Esquistossomose Mansoni. São Paulo, 1957. Tese (Inaugural). Faculdade de Medicina da Universidade de São Paulo.

ROSEMBERG, D.; SARAIVA, J. A. M.; VILELLA, M. P. Avaliação dos resultados da anastomose porto-cava no tratamento cirúrgico da hipertensão portal. J. Bras. Med., v.3, p.609-72, 1960. 
SAAD, W. A.; YAMIN, H.; FREDAY, U.; VELARD, G.; CHAIB, S.; PARRA, O. M.; BERMAN, A.; VASCONCELOS, E. Descompressão seletiva do sistema portal no tratamento da hipertensão portal associada a varizes do esôfago sangrantes.

AMB Rev. Assoc. Med. Bras., v.23, p.165-8, 1977.

SAAD Jr., R. Contribuição ao Estudo das Repercussões da Hipertensão Porta de Etiologia Esquistossomótica nas Veias do Plexo Retal Interno. São Paulo, 1981. Tese (Mestrado). Faculdade Ciências Médicas da Santa Casa de São Paulo.

SAKAI, P. Escleroterapia endoscópica das varizes sangrantes do esôfago em pacientes esquistossomóticos. São Paulo, 1985. Tese (Doutorado) Faculdade de Medicina Universidade de São Paulo.

SAKAI, P.; BOAVENTURA, S.; ISHIOKA, S.; MIES, S.; SETTE, H.; PINOTTI, H. $W$. Sclerotherapy of bleeding esophageal varices in shistosomiasis comparative study in patients with and without previous surgery for portal hypertension. Endoscopy, v.22, p.5-7, 1990.

SAKAI, P. Esclerose Endoscópica das varizes esofágicas após tratamento cirúrgico da hipertensão portal em pacientes com esquistossomose hepatoesplênica. Arq. Gastroenterol., v.38, p.81-2, 2001.

SALAM, A.A.; EZZAT, F.A.; ABU-ELMAGD, K.M. Selective shunt in schistosomiasis in Egypt. Am. J. Sug., v,160, p.90-2, 1990.

SILVA, L. C. Estudo da Hiperbilirrubinemia Pós-Anastomose Porto-Cava em Pacientes com Esquistossomose Hepato-Esplênica e Cirrose Hepática. São Paulo, 1961. Tese (Inaugural) Faculdade de Medicina da Universidade de São Paulo.

SILVA, L. C. Schistosomiasis mansoni - clinical features. In: Okuda, K.; Benhamou, J. P. eds. Portal Hypertension - Clinical and Physiological Aspects Tokyo, Springer-Verlag 1991, p.309-18

SPERANZINI, M. B. Vascularização Arterial do Fígado na Fibrose Hepática Esquistossomótica após Anastomose Espleno-Renal (Estudo 
Angiográfico). São Paulo, 1971. Tese (Livre-Docência) Faculdade de Medicina da Universidade de São Paulo.

STELMACH, D.; CÁPUA Jr., A. Estudo da pressão portal no pós-operatório de doentes esquistossomóticos submetidos a esplenectomia e desvascularização gastro-esofágica. GED gastroenterol., v15, p41-8, 1996.

STRAUSS, E. Fluxo sanguíneo hepático. Contribuição ao seu estudo pelo clareamento do radioxenônio (133Xe) injetado no parênquima hepático por punção transcutânea. São Paulo, 1973. Tese (Doutorado). Faculdade de Medicina da Universidade de São Paulo.

STRAUSS, E. Tratamento medicamentoso da hipertensão portal: realidade ou esperança?. Rev. Bras. Clin. Ter., v.12, p.275-6, 1983.

STRAUSS, E. Hipertensão portal esquistossomótica: análise evolutiva de intercorrências clínicas, dados endoscópicos e laboratoriais em estudo randomizado comparando três tipos de cirurgia. Ribeirão Preto, 1989. Tese (Livre-Docência) - Faculdade de Medicina da Universidade de São Paulo.

STRAUSS, E.; SAKAI, P.; GAYOTTO, L. C. C.; CARDOSO, R. A.; FORSTER, S.; RAIA, S. Size of gastroesophageal varices: its behavior after the surgical treatment of portal hypertension. Rev. Hosp. Clín. Fac. Med. S. Paulo., v.54, p.193-98, 1999.

SUGIURA, M.; FUTUGAWA, S. A new technique for treating esophageal varices. J. Thorac. Cardiovasc. Surg., v.66, p.677-85, 1973.

SUMMERFIELD, F. A. Diagnosis of Cirrhosis and Portal Hypertension. In: BLUMGART, L. H. ed. Surgery of the Liver and Biliary Tract. New York, Churchill Livingstone, 1994, p.1603-11.

SYMMERS, W.S.C. Note on a new form of liver cirrhosis due to the presence of the ova of Bilharzia haematobial J. Pathol. Bacteriol., v.9, p.237-9, 1903.

VIEIRA, A.V.C.; CARONE, E.; COSTA, O.F.; GIGLIO, A. Tratamento do hiperesplenismo por embolização esplênica em uma paciente com câncer de 
ovário para possibilitar a administração de quimioterapia antineoplásica. Rev. Bras. Clín. Terap., v.24, p.185-8, 1998.

WARREN, W. D.; ZEPPA, R.; FOMON, J. J. Selective trans-splenic decompression of gastroesophageal varices by distal splenorenal shunt. Ann. Surg., v.166, p.437-55, 1967. 